\title{
Molecular insights on aging and aqueous-phase processing from ambient biomass burning emissions-influenced Po Valley fog and aerosol
}

\author{
Matthew Brege ${ }^{1}$, Marco Paglione ${ }^{2}$, Stefania Gilardoni ${ }^{2}$, Stefano Decesari ${ }^{2}$, Maria Cristina Facchini ${ }^{2}$, and Lynn \\ R. Mazzoleni ${ }^{1,3}$ \\ ${ }^{1}$ Department of Chemistry, Michigan Technological University, Houghton, MI, USA \\ ${ }^{2}$ Institute of Atmospheric Sciences and Climate, Italian National Research Council, Bologna, Italy \\ ${ }^{3}$ Atmospheric Sciences Program, Michigan Technological University, Houghton, MI, USA
}

Correspondence: Lynn R. Mazzoleni (lrmazzol@mtu.edu)

Received: 22 March 2018 - Discussion started: 14 May 2018

Revised: 21 August 2018 - Accepted: 27 August 2018 - Published: 13 September 2018

\begin{abstract}
To study the influence of regional biomass burning emissions and secondary processes, ambient samples of fog and aerosol were collected in the Po Valley (Italy) during the 2013 Supersito field campaign. After the extent of "fresh" vs. "aged" biomass burning influence was estimated from proton nuclear magnetic resonance $\left({ }^{1} \mathrm{H}\right.$ NMR) and high-resolution time-of-flight aerosol mass spectrometry (HR-ToF-AMS), two samples of fog water and two samples of $\mathrm{PM}_{1}$ aerosol were selected for ultrahigh-resolution Fourier transform ion cyclotron resonance mass spectrometry (FT-ICR MS) analysis. Molecular compositions indicated that the water-soluble organic matter was largely nonpolymeric without clearly repeating units. The selected samples had an atypically large frequency of molecular formulas containing nitrogen and sulfur (not evident in the NMR composition) attributed to multifunctional organonitrates and organosulfates. Higher numbers of organonitrates were observed in aerosol, and higher numbers of organosulfates were observed in fog water. Consistent with the observation of an enhanced aromatic proton signature in the ${ }^{1} \mathrm{H}$ NMR analysis, the average molecular formula double-bond equivalents and carbon numbers were higher in the fresh biomass-burning-influenced samples. The average $\mathrm{O}: \mathrm{C}$ and $\mathrm{H}: \mathrm{C}$ values from FT-ICR MS were higher in the samples with an aged influence $(\mathrm{O}: \mathrm{C}=0.50-0.58$, and $\mathrm{H}: \mathrm{C}=1.31-$ 1.37) compared to those with fresh influence $(\mathrm{O}: \mathrm{C}=0.43-$ 0.48 , and $\mathrm{H}: \mathrm{C}=1.13-1.30$ ). The aged fog had a large set of unique highly oxygenated $\mathrm{CHO}$ fragments in the HRToF-AMS, which reflects an enrichment of carboxylic acids
\end{abstract}

and other compounds carrying acyl groups, highlighted by the NMR analysis. Fog compositions were more oxidized and "SOA (secondary organic aerosol)-like" than aerosols as indicated by their NMR measured acyl-to-alkoxyl ratios and the observed molecular formula similarity between the aged aerosol and fresh fog, implying that fog nuclei must be somewhat aged. Overall, functionalization with nitrate and sulfate moieties, in addition to aqueous oxidation, triggers an increase in the molecular complexity in this environment, which is apparent in the FT-ICR MS results. This study demonstrates the significance of the aqueous phase in transforming the molecular chemistry of atmospheric organic matter and contributing to secondary organic aerosol.

\section{Introduction}

Atmospheric organic aerosol particles are comprised of a complex mixture of numerous individual organic compounds, produced by direct emissions and secondary processes, of which a significant impact is from transformations in the aqueous phase. Surface-emitted primary organic aerosol and volatile organic compounds are transformed in the atmosphere by gas-to-particle-phase conversion, heterogeneous reactions, and aqueous-phase reactions in aerosol water, fog, and cloud droplets (Ervens et al., 2011; Herrmann et al., 2015). The products of these processes are collectively referred to as secondary organic aerosol (SOA). These ag- 
ing reactions happen quickly in the atmosphere, and the observed mass fraction of SOA is larger than that of primary organic aerosol (Zhang et al., 2007, 2011; Ervens et al., 2011; Paglione et al., 2014; Gilardoni et al., 2016). Biomass burning emissions - such as those from forest fires, agricultural land clearing, residential heating, and cooking with biofuels - are important sources of organic carbon to the atmosphere globally (Andreae and Merlet, 2001; Bond et al., 2004; Glasius et al., 2006; Laskin et al., 2015). Biomass burning products include simple organic acids, sugars and anhydrosugars, substituted phenols, polycyclic aromatic hydrocarbons, and other compounds, depending on the type of fuel and burn conditions (Mazzoleni et al., 2007; Pietrogrande et al., 2014a, b; Gilardoni et al., 2016). These water-soluble emissions can serve as precursors for SOA once dissolved in the aqueous phase (Chang and Thompson, 2010; Yu et al., 2014, 2016), and upwards of $50 \%$ of organic matter in fog and cloud droplets remains unidentified (Herckes et al., 2013). Biomass burning emissions can even facilitate droplet nucleation. In fact, laboratory studies indicate that, in addition to hydrophilic species, even refractory "tar balls" emitted from smoldering biomass burning begin to absorb water at high relative humidity (Hand et al., 2005; Laskin et al., 2015).

Atmospheric chemistry models are currently unable to replicate several key aspects of SOA, including SOA concentration levels; chemical oxidation states; degree of functionalization; and the occurrence of high-molecular-weight compounds, such as atmospheric humic-like substances (Ervens et al., 2011; Lee et al., 2013; Nguyen et al., 2013). Aqueousphase reactions in wet aerosol, cloud, and fog droplets have been proposed to improve these SOA observation gaps (Ervens et al., 2011; Gilardoni et al., 2016; Herckes et al., 2013; Laskin et al., 2015), but the current level of understanding regarding aqueous-phase processes is insufficient to include them in models. Laboratory studies focusing on simplified systems of only one or two precursor components have successfully recreated some of the complexity of ambient atmospheric samples (De Haan et al., 2011; Lee et al., 2013; Nguyen et al., 2013; Hawkins et al., 2016; Yu et al., 2016). A number of recent studies focusing on the molecular composition of cloud (Lee et al., 2012; Desyaterik et al., 2013; Pratt et al., 2013; Zhao et al., 2013; Boone et al., 2015; Cook et al., 2017) and fog (Mazzoleni et al., 2010; LeClair et al., 2012; $\mathrm{Xu}$ et al., 2017) chemistry have been reported. Together these studies indicate a clear importance of aqueous-phase reactions for the production of aqueous SOA, including the formation of organonitrates, organosulfates, and nitrooxy organosulfates. Of these, organosulfate formation is thought to happen nearly exclusively in the aqueous phase (Ervens et al., 2011; Herrmann et al., 2015). Along with organonitrates, organosulfates are susceptible to hydrolysis in the aqueous phase, though high kinetic barriers under atmospheric conditions often slow these reactions and allow for the observation of these species in ambient samples (Darer et al., 2011; Hu et al., 2011). Organosulfates are often described in the liter- ature as the products of acid-catalyzed oxidation of biogenic terpenoids (Surratt et al., 2008; Pratt et al., 2013; Schindelka et al., 2013), but they have also been observed in biomasscombustion-influenced cloud water (Zhao et al., 2013; Cook et al., 2017). The formation of aqueous-phase products in aerosol, fog, and cloud waters greatly increases the complexity of organic aerosol. Although several analytical techniques have been used to address the challenge of resolving the complex mixture of atmospheric organic matter (Decesari et al., 2007; Hertkorn et al., 2007; Nizkorodov et al., 2011; Desyaterik et al., 2013; Dall'Osto et al., 2015; Noziere et al., 2015; Laskin et al., 2016; Willoughby et al., 2016), no universal analytical method exists.

The Po Valley (Italy) has ideal ambient conditions for studying aqueous-phase influences on atmospheric organic matter. The valley contains a mixture of densely populated areas and intensively cultivated agricultural regions. Surrounded by mountains to the north, west, and south, the valley frequently has stable meteorological conditions with low ventilation and a low boundary layer, allowing for the accumulation of high concentrations of regional pollutants. Consequently, frequent fog events and high concentrations of anthropogenic biomass burning emissions are observed in months with cold temperatures (Larsen et al., 2012; Saarikoski et al., 2012; Giulianelli et al., 2014; Paglione et al., 2014; Gilardoni et al., 2016). The Po Valley has some of the highest reported carbon concentrations for fog water in the world (Herckes et al., 2013). In recent years, the analysis of fog water and aerosol from San Pietro Capofiume (SPC, located $30 \mathrm{~km}$ northeast of the city of Bologna) has included Aerodyne high-resolution time-offlight aerosol mass spectrometry (HR-ToF-AMS) and proton nuclear magnetic resonance spectroscopy $\left({ }^{1} \mathrm{H}\right.$ NMR) to determine the fog scavenging efficiency of aerosol (Gilardoni et al., 2014) and source apportionment of aerosol (Decesari et al., 2007). In Saarikoski et al. (2012), HR-ToF-AMS data from SPC aerosol showed an extremely high concentration of aerosol nitrate $(39 \%)$ and a somewhat typical concentration of organic carbon (33\%), in agreement with Gilardoni et al. (2014). Positive matrix factorization (PMF) of HR-ToF-AMS organic mass fragments was used to identify several factors describing Po Valley organic aerosol, including factors for fresh biomass burning organic aerosol, and three types of oxygenated organic aerosol (Saarikoski et al., 2012). A similar study by Paglione et al. (2014) used PMF on ${ }^{1} \mathrm{H}-\mathrm{NMR}$ data of SPC aerosol to identify factors for fresh biomass burning emissions, as well as SOA factors, including products formed from aged biomass burning emissions.

Further investigation with a focus on molecular markers and source apportionment was done as part of the $2013 \mathrm{Su}-$ persito field campaign in the Emilia-Romagna region, including samples from SPC and the urban site of Bologna (Pietrogrande et al., 2014a, b; Poluzzi et al., 2015). The campaign has shown the significance of biomass burning emissions in the region. Approximately $35 \%$ of the organic carbon was 
from wood burning in winter months (Pietrogrande et al., 2015), biomass burning emissions were shown to increase with decreasing ambient temperature (Gilardoni et al., 2014), and aqueous-phase SOA formation from biomass burning emissions and associated brown carbon formation was directly observed (Gilardoni et al., 2016). HR-ToF-AMS observations have shown similarity between atmospheric organic matter in fog water and aerosol formed following fog dissipation, indicating that low-volatility organics that were originally present in the fog are left behind upon evaporation; these particles are enriched in oxidized organic matter and absorb solar radiation more efficiently than fresh emissions, contributing to atmospheric brown carbon (Gilardoni et al., 2016).

In this study, we analyzed fog from SPC and aerosol from Bologna, collected during the 2013 Supersito field campaign. Due to the intense time investment required for Fourier transform ion cyclotron resonance mass spectrometry (FT-ICR MS) data analysis, we chose to focus our detailed analysis on a subset of samples, including two aerosol and two fog samples. The subset was selected to represent the influence of fresh and aged biomass burning emissions on fog and aerosol based on the HR-ToF-AMS and ${ }^{1} \mathrm{H}-\mathrm{NMR}$ observations (Sect. 3.1). We used a combination of ${ }^{1} \mathrm{H}-\mathrm{NMR}$, HR-ToF-AMS, and FT-ICR MS techniques to explore the molecular-level details of the complex mixtures of atmospheric organic matter in the Po Valley. Similar studies focusing on analysis of atmospheric samples with ${ }^{1} \mathrm{H}$ NMR and FT-ICR MS have been conducted in the past (SchmittKopplin et al., 2010; Willoughby et al., 2016), but this type of study with a focus on biomass burning and aqueous-phase processing has not yet been reported.

\section{Methods}

\subsection{Sample collection and chemical analysis}

Sub-micrometer $\left(\mathrm{PM}_{1}\right)$ aerosol particles were collected in Bologna on pre-washed and pre-baked quartz fiber filters (PALL, $18 \mathrm{~cm}$ diameter) by a high-volume sampler (TECORA Echo Hi Vol) equipped with a digital $\mathrm{PM}_{1}$ sampling inlet at a nominal flow rate of $500 \mathrm{~L} \mathrm{~min}^{-1}$. $\mathrm{PM}_{1}$ samples were collected during winter 2013 (from 4 to 15 February 2013), during the Supersito project. Fog water was collected at the SPC field station, where monitoring of fog occurrence and fog water collection has been performed every year systematically since 1989 (Giulianelli et al., 2014); during the 2013 winter fog samples were collected from 29 November 2012 to 12 March 2013. In the fog collector (Fuzzi et al., 1997), a short wind tunnel is created by a rear fan, where an air stream containing fog droplets are collected by impaction using a series of stainless-steel strings. The collected droplets drain off the strings into a sampling bottle. The air flow through the tunnel was $17 \mathrm{~m}^{3} \mathrm{~min}^{-1}$ with a $50 \%$ collection efficiency for individual strings ( $3 \mu \mathrm{m}$ radius each). All parts of the fog collector coming into contact with the fog droplets were made of stainless steel to avoid sampling artifacts from adsorption of organic compounds to the surfaces.

The aerosol filters were extracted with deionized ultrapure water (Milli-Q) in an ultrasonic bath for $1 \mathrm{~h}$. The water extract was filtered with a $0.45 \mu \mathrm{m}$ PTFE membrane in order to remove suspended particles. Fog water was filtered through $47 \mathrm{~mm}$ quartz fiber filters within a few hours of collection, and conductivity and $\mathrm{pH}$ measurements were taken (Crison microCM 2201 conductometer and Crison micropH $2002 \mathrm{pH}$ meter). Aliquots of both aerosol water extracts and fog water prepared in this way were used to determine the total organic carbon content (Multi N/C 2100 analyzer; Analytik Jena, Germany) and water soluble organic carbon (WSOC) concentration, (Rinaldi et al., 2007) as well as for ${ }^{1} \mathrm{H}-\mathrm{NMR}$ analysis and HR-ToF-AMS analysis of fog samples described below (HR-ToF-AMS data for aerosol samples were collected in real time).

\section{$2.2 \quad{ }^{1}$ H-NMR analysis}

Aliquots of the aerosol extract and fog water were dried under vacuum and re-dissolved in deuterium oxide $\left(\mathrm{D}_{2} \mathrm{O}\right)$ for organic functional group characterization by ${ }^{1} \mathrm{H}-\mathrm{NMR}$ spectroscopy, as described in Decesari et al. (2000). The ${ }^{1} \mathrm{H}-\mathrm{NMR}$ spectra were acquired at $600 \mathrm{MHz}$ (Varian Unity INOVA spectrometer) with a $5 \mathrm{~mm}$ probe. Sodium 3trimethylsilyl-(2,2,3,3-d4) propionate (TSP-d4) was used as an internal standard by adding $50 \mu \mathrm{L}$ of a $0.05 \%$ TSP-d4 (by weight) in $\mathrm{D}_{2} \mathrm{O}$ to the standard in the probe. The speciation of hydrogen atoms bound to carbon atoms can be provided by ${ }^{1} \mathrm{H}-\mathrm{NMR}$ spectroscopy in protic solvents; on the basis of the range of frequency shifts, the signal can be attributed to $\mathrm{HC}$ containing specific functionalities (Decesari et al., 2000, 2007). Detection limits for an average sampling volume of $500 \mathrm{~m}^{3}$ were on the order of $3 \mathrm{nmol} \mathrm{m}^{-3}$ for each functional group. ${ }^{1} \mathrm{H}$-NMR spectra were collected during the winter 2013 campaign using the method described above to identify and quantify major components of WSOC in both fog and aerosol. In the present study, the results of these ${ }^{1} \mathrm{H}-\mathrm{NMR}$ analyses were used to characterize and to select the samples for subsequent FT-ICR MS analysis as described in Sect. 3.1.

\subsection{HR-ToF-AMS analysis}

During the Supersito winter 2013 campaign (4 to 15 February 2013) the chemical composition of $\mathrm{PM}_{1}$ aerosol particles at Bologna was characterized with a 5 min time resolution using an HR-ToF-AMS (Aerodyne Research; DeCarlo et al., 2006). Data were collected in the V-ion mode, at a resolution of 2200. The influx of aerosol particles was dried below $30 \%$ relative humidity with a Nafion drier before analysis. Details on analysis of HR-ToF-AMS data for the Supersito winter 2013 campaign were previously reported (Gilardoni 
et al., 2016); here we report HR-ToF-AMS characterization averaged over the sampling periods of the selected aerosol samples.

Fog water samples were also analyzed by HR-ToF-AMS after being re-aerosolized (TSI constant output atomizer, Model \#3076) in an inert argon gas flow to characterize dissolved water-soluble organics. To make sure that the reaerosolized fog water represented the original sample, we verified that the nitrate-to-organic-carbon and the sulfate-toorganic-carbon ratios from the HR-ToF-AMS analysis were within $20 \%$ (measurement uncertainty level) of the ratios measured offline by ion chromatography and thermo-optical analysis.

\subsection{Ultrahigh-resolution FT-ICR MS analysis}

Four samples were selected for FT-ICR MS analysis based on the characterization by HR-ToF-AMS data and ${ }^{1} \mathrm{H}-\mathrm{NMR}$ spectra for the entire Supersito winter 2013 sample set (Sect. 3.1). High-molecular-weight WSOC compounds were prepared for FT-ICR MS analysis using a reversed-phase polymeric solid-phase extraction (SPE) cartridge (Strata$\mathrm{X}$, Phenomenex) to remove salts and low-molecular-weight compounds which interfere with electrospray ionization (ESI). The cartridges were loaded with $\mathrm{HCl}$-acidified aqueous samples $(\mathrm{pH}<2)$, rinsed with $1 \mathrm{~mL}$ of water, and then eluted using $2 \mathrm{~mL}$ of $\mathrm{ACN}: \mathrm{H}_{2} \mathrm{O}$ ( $90: 10$ by volume). Fog samples were later re-filtered using a $25 \mathrm{~mm}$ quartz filter before SPE. A portion of the aerosol filter samples were extracted with ultrapure water using sonication, and the extracts were then filtered using a $25 \mathrm{~mm}$ quartz filter to remove insoluble materials; the aerosol extracts were then prepared for FT-ICR MS analysis using SPE as described above. The WSOC described in this paper is operationally defined as the WSOC that is both retained and recovered from the SPE cartridges (SPE-recovered); thus it is not equivalent to the total WSOC. The ACN: $\mathrm{H}_{2} \mathrm{O}$ extracts were analyzed at the Woods Hole Oceanographic Institute in Woods Hole, MA, USA, using full-scan ESI ultrahigh-resolution FT-ICR MS (7 T LTQ FT-ICR MS, Thermo Scientific) at a resolving power of 400000 as described in our previous work (Zhao et al., 2013; Dzepina et al., 2015). We used direct infusion analysis to collect mass spectrometry data over the mass range of $m / z 100-1000$ in the negative ionization mode, for approximately 200 scans. Molecular formulas were assigned as previously described in our work (Dzepina et al., 2015; Mazzoleni et al., 2010; Putman et al., 2012; Zhao et al., 2013) using Sierra Analytics Composer software (version 1.0.5) within the limits of $\mathrm{C}_{2-200} \mathrm{H}_{4-1000} \mathrm{O}_{1-20} \mathrm{~N}_{0-3} \mathrm{~S}_{0-1}$. The formulas were reviewed manually for their credibility; for further details, see the Supplement. Approximately $74 \%$ of the measured masses in each of the samples were assigned a molecular formula. Oxygen-to-carbon $(\mathrm{O}: \mathrm{C})$ and hydrogento-carbon $(\mathrm{H}: \mathrm{C})$ ratios were calculated from the respective number of $\mathrm{C}, \mathrm{H}$, or $\mathrm{O}$ atoms in the assigned molecular formu- las. We calculated Kendrick mass (KM) and Kendrick mass defect (KMD) as described in Eqs. (1) and (2), respectively (Stenson et al., 2003).

$\mathrm{KM}=$ experimental mass $\cdot\left(\frac{14.00000}{14.01565}\right)$

$\mathrm{KMD}=$ nominal mass $-\mathrm{KM}$

The number of double-bond equivalents (DBEs) was calculated by Eq. (3) for the molecular formula format: $\mathrm{C}_{c} \mathrm{H}_{h} \mathrm{O}_{o} \mathrm{~N}_{n} \mathrm{~S}_{s}$.

$\mathrm{DBE}=c-\left(\frac{h}{2}\right)+\left(\frac{n}{2}\right)+1$

Note that $\mathrm{S}$ and $\mathrm{O}$ are divalent in Eq. (3); additional unsaturated bonds associated with pentavalent nitrogen, and tetravalent or hexavalent sulfur, are not included in this DBE calculation. The average oxidation state of carbon $\left(\mathrm{OS}_{\mathrm{C}}\right)$ in the molecular formulas was estimated using Eq. (4), based on the approximation described in Kroll et al. (2011); note that the inclusion of nitrogen and sulfur affects the oxidation state of carbon, and Eq. (4) assumes both are fully oxidized. The modified aromaticity index $\left(\mathrm{AI}_{\mathrm{mod}}\right)$ (Koch and Dittmar, 2006, 2016) was calculated using Eqs. (5)-(7). Equations (4)-(7) use the same molecular formula format as DBE in Eq. (3).

$\mathrm{OS}_{\mathrm{C}} \approx 2 \frac{o}{c}-\frac{h}{c}-5 \frac{n}{c}-6 \frac{s}{c}$
$\mathrm{DBE}_{\mathrm{AI}}=1+c-\left(\frac{o}{2}\right)-s-\left(\frac{n+h}{2}\right)$
$\mathrm{C}_{\mathrm{AI}}=c-\left(\frac{o}{2}\right)-n-s$
$\mathrm{AI}_{\mathrm{mod}}=\frac{\mathrm{DBE}_{\mathrm{AI}}}{\mathrm{C}_{\mathrm{AI}}}$

In Eq. (7), the $\mathrm{AI}_{\text {mod }}=0$ if $\mathrm{DBE}_{\mathrm{AI}} \leq 0$ or $\mathrm{C}_{\mathrm{AI}} \leq 0$, as defined in Koch and Dittmar (2006, 2016).

The resulting data set represents the SPE-recovered higher-molecular-weight water-soluble organic aerosol and is expected to predominantly contain acidic compounds due to the negative-ion ESI analytical biases. The observed molecular compositions represent the oxidized fraction of the atmospheric samples; thus, useful insights can be made with these limitations in mind. Furthermore, it is important to note that the individual molecular formulas likely represent a mixture of structural isomers co-existing in atmospheric organic matter, as recently observed for deep-sea organic matter (Zark et al., 2017).

\section{Results and discussion}

\subsection{Selection of aerosol and fog water samples}

Among the 15 fog and 18 aerosol samples collected during the winter of 2013 at SPC and Bologna, we selected 
(a) AMS relative intensities

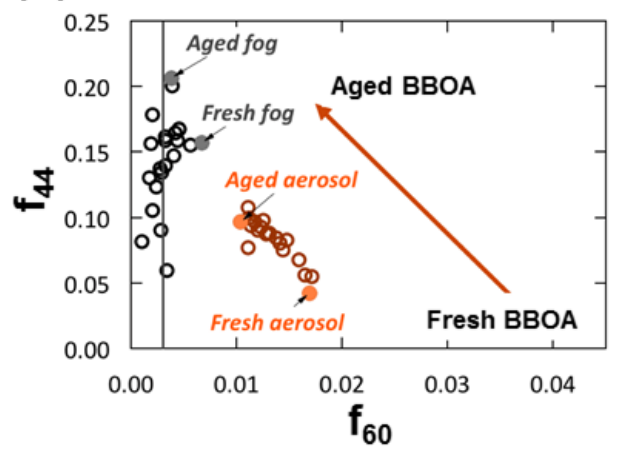

(b) NMR functional group distribution

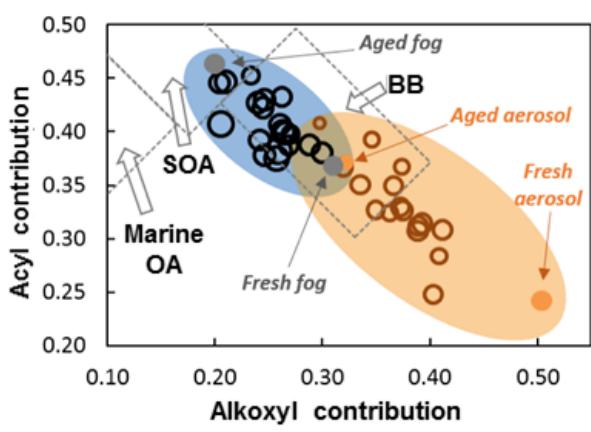

Aromatic/

aliphatic

0.3

O 0.2

○ 0.1

Figure 1. Preliminary characterization of fog and $\mathrm{PM}_{1}$ aerosol samples collected in SPC and Bologna, respectively, during the 2013 Supersito field campaign. Characterization was performed via HRToF-AMS analysis as described by Cubison et al. (2011), utilizing the relative intensity of peak $\mathrm{m} / z 60\left(f_{60}\right)$ and peak $\mathrm{m} / z 44$ $\left(f_{44}\right)$ as markers of fresh biomass burning influence and oxygenated and processed dissolved organic molecules, respectively (a). Further characterization was performed via ${ }^{1} \mathrm{H}-\mathrm{NMR}$ analysis, as described by Decesari et al. (2007), where samples were mapped by ${ }^{1} \mathrm{H}-\mathrm{NMR}$ functional group fractions (b). In (b), dashed lines indicate the boundaries of the source fingerprints according to Decesari et al. (2007; "BB": biomass burning aerosol), and the $x$ and $y$ axes report the contributions of alkoxyl $(\mathrm{HCO})$ and acyl $(\mathrm{HCC}=\mathrm{O})$ groups to the total aliphatic fraction of WSOC, respectively. The sample names fresh fog, aged fog, fresh aerosol, and aged aerosol correspond to SPC0106F, SPC0201F, BO0204N, and BO0213D, respectively.

two fog and two aerosol samples for subsequent analysis by FT-ICR MS according to the following rationale. Aerosol samples were selected based on PMF source apportionment of "fresh" and "aged" wood burning emissions using HRToF-AMS and ${ }^{1} \mathrm{H}-\mathrm{NMR}$ data, as described in Gilardoni et al. (2016). On 13 February 2013, a high concentration of SOA was observed, where the ratio of SOA to POA was $\sim 4$, and the aqueous SOA from biomass burning accounted for about $55 \%$ of total SOA. Thus, BO0213D was defined as strongly influenced by aged wood burning emissions. During the night of 4 February 2013, the fresh biomass burning concentration was $\sim 6 \mu \mathrm{g} \mathrm{m}^{-3}$, accounting for $54 \%$ of total or-

ganic aerosol. Thus, BO0204N was defined as strongly influenced by fresh wood burning emissions. Similarly, HR-ToFAMS observations were used to select fog samples strongly impacted by fresh and aged wood burning emissions. Specifically, we used the relative intensity of $m / z \quad 60\left(f_{60}\right)$ as a marker of fresh biomass burning influence and $m / z 44$ $\left(f_{44}\right)$ as a marker of oxygenated and processed dissolved organic molecules (Aiken et al., 2008; Gilardoni et al., 2016). The $f_{44}$ vs. $f_{60}$ space was previously proposed to represent biomass burning vs. atmospheric aerosol aging (Cubison et al., 2011) and was extended here to fog samples. We are aware that this representation is an oversimplification of the complexity of organic molecules in fog water; thus this approach is employed here exclusively to spot marked differences in terms of different sources and atmospheric history of sample organic content. In Fig. 1a, it can be seen that the fog sample SPC0106F had low $f_{44}$ and high $f_{60}$ values, while SPC0201F had high $f_{44}$ and low $f_{60}$ values. Thus, from here on, SPC0106F (fog) and BO0204N (aerosol) will be referred to as the "fresh" biomass-burning-influenced samples, and SPC0201F (fog) and BO0213D (aerosol) will be referred to as the "aged" biomass-burning-influenced samples. A summary of the sample collection details and HRToF-AMS characterization is given in Table 1 .

\section{$3.2{ }^{1} \mathrm{H}-\mathrm{NMR}$ composition}

Functional group distributions for the selected $\mathrm{PM}_{1}$ and fog samples were provided by ${ }^{1} \mathrm{H}-\mathrm{NMR}$ analysis. A synthetic representation of the ${ }^{1} \mathrm{H}-\mathrm{NMR}$ organic functional group distribution of all the collected samples is reported in Fig. 1b, following the approach described by Decesari et al. (2007) for source attribution. Briefly, Decesari et al. (2007) presented a survey of ${ }^{1} \mathrm{H}$-NMR functional group distributions of WSOC samples from diverse environments, proposing fingerprints for broad categories of oxygenated organic compounds in aerosol. These categories are SOA (enriched in acyl groups, $\mathrm{HCC}=\mathrm{O}$ ), biomass burning aerosol (enriched in alkoxyls, $\mathrm{HCO}$, and aromatics), and marine organic aerosol (enriched in aliphatic groups other than acyls and alkoxyls, mainly amines and sulfoxy groups). In this study, most samples were categorized either as SOA or as biomass burning, even if a significant fraction of the aerosol samples exhibited ${ }^{1} \mathrm{H}-\mathrm{NMR}$ compositions with a very high alkoxyl contribution exceeding the boundaries proposed by Decesari et al. (2007). For example, sample BO0204N (representative of fresh biomass burning aerosol) showed by far the largest contribution of alkoxyl groups and the least amount of acyl groups. In contrast, BO0213D (representative of aged aerosols) showed relatively high acyl content and small alkoxyl fractions. Similarly, the two selected fog samples (SPC0106F: fresh; SPC0201F: aged) were clearly differentiated based on their ${ }^{1} \mathrm{H}-\mathrm{NMR}$ functional group distributions (Fig. 1b). Therefore, the selected aerosol and fog samples represent extremes in the structural space of this WSOC 
Table 1. Sample collection, identification and HR-ToF-AMS data. Relative humidity (RH), liquid water content (LWC), and aerosol liquid water content (ALWC) are averaged over the sample collection time. Fog samples were collected at San Pietro Capofiume (SPC). Fog water samples were re-aerosolized for HR-ToF-AMS data analysis, while aerosol sample data are from online measurements. For aerosol samples, the standard deviation of online measurements corresponding to the sample collection period is shown.

\begin{tabular}{|c|c|c|c|c|}
\hline Sample name & SPC01016F & SPC0201F & BO0204N & BO0213D \\
\hline Collection site & SPC & SPC & Bologna & Bologna \\
\hline Sample type & Fog water & Fog water & $\mathrm{PM}_{1}$ aerosol & $\mathrm{PM}_{1}$ aerosol \\
\hline $\begin{array}{l}\text { Fresh vs. aged } \\
\text { influence }\end{array}$ & Fresh & Aged & Fresh & Aged \\
\hline $\begin{array}{l}\text { Start collection } \\
\text { date and time }\end{array}$ & 6 Jan 2013, 3:10 & 1 Feb 2013, 19:40 & 4 Feb 2013, 18:18 & 13 Feb 2013, 9:24 \\
\hline Collection time (h) & 1.33 & 15.37 & 14.62 & 8.60 \\
\hline Temperature $\left({ }^{\circ} \mathrm{C}\right)^{\mathrm{b}}$ & 1.0 & 3.0 & 5.9 & 3.0 \\
\hline $\mathrm{pH}$ & 5.81 & 3.34 & NA & NA \\
\hline$\left[\mathrm{NO}_{X}\right](\mathrm{ppb})^{\mathrm{b}}$ & 73 & 15 & 146 & 101 \\
\hline $\mathrm{RH}(\%)^{\mathrm{b}, \mathrm{c}}$ & 100 & 100 & 58 & 80 \\
\hline $\operatorname{LWC}\left(\mathrm{mL} \mathrm{m}^{-3}\right)^{\mathrm{b}}$ & 0.190 & 0.258 & NA & NA \\
\hline $\operatorname{ALWC}\left(\mu \mathrm{g} \mathrm{m}^{-3}\right)^{\mathrm{b}, \mathrm{d}}$ & NA & NA & 69 & 515 \\
\hline$f_{44}^{\mathrm{e}}$ & 0.16 & 0.21 & $0.042 \pm 0.006$ & $0.097 \pm 0.004$ \\
\hline$f_{60}^{\mathrm{e}}$ & 0.007 & 0.004 & $0.016 \pm 0.003$ & $0.010 \pm 0.001$ \\
\hline OM:OC ${ }^{b, f}$ & 1.9 & 2.2 & $1.5 \pm 0.1$ & $1.9 \pm 0.1$ \\
\hline $\mathrm{O}: \mathrm{C}^{\mathrm{b}, \mathrm{f}}$ & 0.58 & 0.8 & $0.24 \pm 0.04$ & $0.56 \pm 0.03$ \\
\hline$H: C^{b, f}$ & 1.37 & 1.29 & $1.65 \pm 0.03$ & $1.60 \pm 0.01$ \\
\hline $\mathrm{OS}_{\mathrm{C}}^{\mathrm{b}, \mathrm{f}}$ & -0.21 & 0.32 & $-1.17 \pm 0.08$ & $-0.48 \pm 0.06$ \\
\hline
\end{tabular}

${ }^{a}$ Start collection times given in local time. ${ }^{b}$ Average values corresponding to the collection times of individual samples. ${ }^{c}$ Average RH was assumed to be $100 \%$ for fog samples, as supersaturation levels could not be measured. ${ }^{\mathrm{d}}$ ALWC is an average of E-AIM and ISORROPIA modeled data for the sampling period. ${ }^{\mathrm{e}}$ Fractional abundance of a mass fragment $\left(f_{X}\right)$ was calculated as the ratio between that fragment signal and the total organic concentration. ${ }^{\mathrm{f}}$ Elemental ratios were calculated according to Aiken et al. (2008).

sample set based on the distribution of ${ }^{1} \mathrm{H}-\mathrm{NMR}$ functionalities and in agreement with the categorization provided by the HR-ToF-AMS measurements.

The differences between the two aerosol samples likely reflect the ambient conditions during sampling: BO0204N was characterized by nighttime accumulation of ground-level local emissions from residential heating and an absence of photochemical processes; instead, BO0213D was characterized by daytime photochemically processed aerosol and by an enhanced mixing with regional-scale air masses. Similarly, the diversity in the fog samples reflects the collection duration and the associated liquid water content (LWC) of the two fog events considered: SPC0106F was collected over a shorter duration with a lower LWC compared to SPC0201F (Table 1).

It should be noted that, although a pair of fresh and aged samples were selected from each of the sample sets, Fig. 1 shows a clear shift in the average composition between the fog and the aerosol samples, where the fog samples were characterized by a greater amount of acyl groups and a smaller fraction of alkoxyls. So, according to the simple source-attribution scheme based on the major ${ }^{1} \mathrm{H}-\mathrm{NMR}$ functionalities presented here, the fog compositions were more oxidized and "SOA-like" than aerosols. As a consequence, the fresh fog composition overlapped with the aged aerosol composition (Fig. 1b). This implies that the fresh fog sample SPC0106F was processed to a degree similar to that of the most aged aerosol sample, BO0213D. This was confirmed by the corresponding HR-ToF-AMS elemental ratios (very similar O : C for SPC0106F and BO0213D; see Table 1) and by the detailed comparison between the ${ }^{1} \mathrm{H}-\mathrm{NMR}$ spectra of these two samples (one fog and one aerosol). This difference in the average functional group composition between fog and aerosol samples in the Po Valley can be explained by (a) the preferential scavenging of more oxidized constituents of organic particles into fog (Gilardoni et al., 2014), (b) the effect of oxidative chemical reactions in fog water leading to the production of carboxylic acids and carbonyls (and hence acyls), and (c) a stronger aging effect from fog processing at the rural site (SPC) with respect to urban areas (Bologna) at the margins of the Po Basin.

The ${ }^{1} \mathrm{H}-\mathrm{NMR}$ spectra of the selected samples are reported in Fig. 2. The spectra of the aerosol samples (Fig. 2c and d) exhibited a clear biomass burning fingerprint, with evident proton resonances from levoglucosan and intense bands from alkoxyl (HCO) and aromatic (ArH) groups. However, the band of phenols and methoxyphenols, which are primary biomass burning tracers, were clearly found only in the spectrum of BO0204N, representative of fresh primary organic aerosols in our study. Moreover, the fraction of levoglucosan 


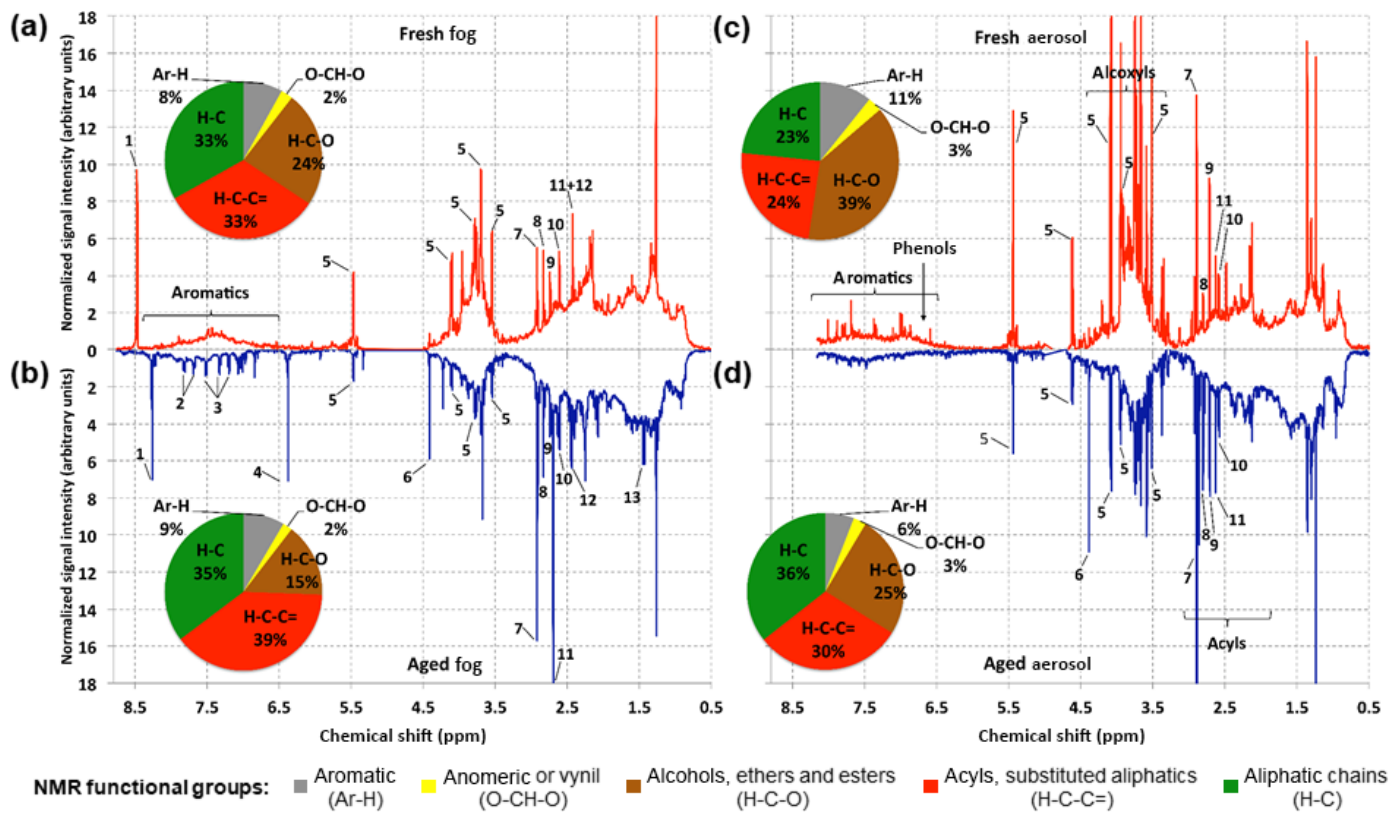

Figure 2. The ${ }^{1} \mathrm{H}-\mathrm{NMR}$ spectra of selected fog water $(\mathbf{a}, \mathbf{b})$ and aerosol $(\mathbf{c}, \mathbf{d})$ samples, and their corresponding functional group distribution. A set of specific resonances was attributed to individual compounds: (1) formate, (2) phthalic acid, (3) ammonium, (4) maleic acid, (5) levoglucosan, (6) hydroxy-methanesulfonic acid, (7) trimethylamine, (8) methanesulfonic acid, (9) dimethylamine, (10) monomethylamine, (11) succinic acid, (12) pyruvic acid, and (13) lactic acid. The sample names fresh fog, aged fog, fresh aerosol, and aged aerosol correspond to SPC0106F, SPC0201F, BO0204N, and BO0213D, respectively.

and alkoxyl groups was much greater in BO0204N than in BO0213D. The aged aerosol BO0213D contained higher amounts of two methylamines (mono- and trimethylamines) relative to $\mathrm{BO} 0204 \mathrm{~N}$, and especially much larger fractions of methanesulfonate and succinic acid, which are tracers of SOA. The spectral region between the chemical shift of 2.1 and $2.4 \mathrm{ppm}$ showed clear bands representing aliphatic dicarboxylic acids and ketoacids (Suzuki et al., 2001) in the aged aerosol but were barely visible in the fresh aerosol. The aged aerosol was also characterized by the occurrence of hydroxy-methanesulfonic acid (HMSA), a known tracer of aqueous SOA. Similarly for fog, SPC0106F (Fig. 2a) exhibited a clear biomass burning fingerprint with contributions from levoglucosan, alkoxyl (HCO), and aromatic groups (ArH), whereas SPC0201F (Fig. 2b) showed tracers of aqueous-phase SOA (HMSA) and high concentrations of acyl groups $(\mathrm{CHC}=\mathrm{O})$, which demonstrated the effects of the aging process. Additionally, SPC0201F exhibited several low-molecular-weight organic acids (phthalic, maleic, succinic, pyruvic, and lactic acids) in much greater amounts than SPC0106F, where only traces of phthalic and succinic acids were found. This indicated that the aged fog was enriched in products of the oxidative degradation of particulate and gaseous organic compounds. It should be noted that the fresh fog (SPC0106F) did not show the prominent band from phenols or methoxyphenols observed in the spectrum of the fresh aerosol (BO0204N). This suggests that the WSOC of the fresh fog had undergone a certain degree of chemical modification respective to primary biomass burning OA.

\subsection{Ultrahigh-resolution FT-ICR MS composition}

\subsubsection{Overview of the compositions of Po Valley ambient fog and aerosol}

Approximately 1600-2800 individual monoisotopic molecular formulas were assigned to the ultrahigh-resolution mass spectra of the SPE-recovered WSOC from each Po Valley sample. Based on the inclusion of $\mathrm{C}, \mathrm{H}, \mathrm{N}, \mathrm{O}$, and $\mathrm{S}$ elements, the molecular formulas were sorted into the following elemental groups: "CHO," "CHNO," "CHOS", and "CHNOS". The percent composition of these elemental groups for each sample is shown in Fig. 3. Most of the molecular formulas were present in the subclasses $\mathrm{O}_{4-10}, \mathrm{NO}_{3-13}, \mathrm{O}_{5-10} \mathrm{~S}$, and $\mathrm{NO}_{7-11} \mathrm{~S}$ (Fig. S1 in the Supplement). A summary of the observed numbers of formulas per elemental group as well as the average $\mathrm{O}: \mathrm{C}, \mathrm{H}: \mathrm{C}, \mathrm{OS}_{\mathrm{C}}$, and $\mathrm{DBE}$ values is provided in Table 2. Although they are not expected to match, the values for the SPE-recovered WSOC do trend with those from the HR-ToF-AMS data shown in Table 1; we note that not only are the elemental ratios from different fractions of the aerosol, but they are also determined differently.

A great diversity of CHNO, CHOS, and CHNOS formulas were observed in the Po Valley samples, likely representing organonitrates, organosulfates, and nitrooxy organosul- 
Table 2. Summary of FT-ICR MS formula assignment data. Mass, O : C, H:C, $\mathrm{OS}_{\mathrm{C}}$, DBE, AI, $\mathrm{C}_{n}$, and $\mathrm{O}_{n}$ values represent mathematical averages based on formula assignment, with standard deviation provided. These values were obtained using Eqs. (1)-(7).

\begin{tabular}{|c|c|c|c|c|c|c|}
\hline & & All & $\mathrm{CHO}$ & CHNO & CHOS & CHNOS \\
\hline \multirow[t]{9}{*}{ SPC0106F } & Number & 2824 & $1158(41 \%)$ & $744(26 \%)$ & $619(22 \%)$ & $303(11 \%)$ \\
\hline & Molecular weight (Da) & $368.44 \pm 94.21$ & $359.05 \pm 101.35$ & $342.88 \pm 90.69$ & $404.68 \pm 83.64$ & $393.12 \pm 61.72$ \\
\hline & $\mathrm{O}: \mathrm{C}$ & $0.479 \pm 0.16$ & $0.415 \pm 0.13$ & $0.503 \pm 0.14$ & $0.488 \pm 0.14$ & $0.642 \pm 0.18$ \\
\hline & $\mathrm{H}: \mathrm{C}$ & $1.30 \pm 0.36$ & $1.21 \pm 0.32$ & $1.14 \pm 0.27$ & $1.56 \pm 0.34$ & $1.53 \pm 0.34$ \\
\hline & $\mathrm{OS}_{\mathrm{C}}$ & $-0.623 \pm 0.48$ & $-0.379 \pm 0.42$ & $-0.563 \pm 0.33$ & $-0.950 \pm 0.49$ & $-1.039 \pm 0.37$ \\
\hline & $\mathrm{DBE}$ & $7.24 \pm 3.65$ & $8.29 \pm 3.67$ & $8.35 \pm 3.01$ & $4.93 \pm 3.08$ & $5.20 \pm 2.93$ \\
\hline & $\mathrm{AI}_{\text {mod }}$ & $0.24 \pm 0.22$ & $0.31 \pm 0.20$ & $0.32 \pm 0.21$ & $0.08 \pm 0.12$ & $0.06 \pm 0.11$ \\
\hline & $\mathrm{C}_{n}$ & $17.2 \pm 5.2$ & $18.3 \pm 5.5$ & $15.7 \pm 4.9$ & $17.8 \pm 4.8$ & $15 \pm 3.7$ \\
\hline & $\mathrm{O}_{n}$ & $7.8 \pm 2.3$ & $7.4 \pm 2.5$ & $7.6 \pm 2.2$ & $8.3 \pm 2.0$ & $9.1 \pm 1.3$ \\
\hline \multirow[t]{9}{*}{ SPC0201F } & Number & 1671 & $890(53 \%)$ & $427(26 \%)$ & $212(13 \%)$ & $142(8 \%)$ \\
\hline & Molecular weight (Da) & $360.12 \pm 97.52$ & $358.18 \pm 108.61$ & $364.33 \pm 90.94$ & $360.12 \pm 78.27$ & $359.66 \pm 63.56$ \\
\hline & $\mathrm{O}: \mathrm{C}$ & $0.577 \pm 0.18$ & $0.509 \pm 0.13$ & $0.617 \pm 0.14$ & $0.592 \pm 0.15$ & $0.858 \pm 0.24$ \\
\hline & $\mathrm{H}: \mathrm{C}$ & $1.31 \pm 0.35$ & $1.18 \pm 0.29$ & $1.23 \pm 0.26$ & $1.74 \pm 0.23$ & $1.77 \pm 0.20$ \\
\hline & $\mathrm{OS}_{\mathrm{C}}$ & $-0.399 \pm 0.51$ & $-0.161 \pm 0.41$ & $-0.369 \pm 0.28$ & $-1.006 \pm 0.42$ & $-1.075 \pm 0.35$ \\
\hline & DBE & $6.83 \pm 3.53$ & $8.05 \pm 3.38$ & $7.49 \pm 2.69$ & $3.01 \pm 1.81$ & $2.93 \pm 1.13$ \\
\hline & $\mathrm{AI}_{\text {mod }}$ & $0.22 \pm 0.21$ & $0.30 \pm 0.19$ & $0.22 \pm 0.20$ & $0.00 \pm 0.03$ & $0.00 \pm 0.00$ \\
\hline & $\mathrm{C}_{n}$ & $15.8 \pm 5.0$ & $16.9 \pm 5.2$ & $15.4 \pm 4.4$ & $14.4 \pm 4.0$ & $11.8 \pm 3.4$ \\
\hline & $\mathrm{O}_{n}$ & $8.7 \pm 2.7$ & $8.5 \pm 3.0$ & $9.2 \pm 2.4$ & $8.2 \pm 2.0$ & $9.5 \pm 1.6$ \\
\hline \multirow[t]{9}{*}{ BO0204N } & Number & 1634 & $808(49 \%)$ & $732(45 \%)$ & $42(3 \%)$ & $52(3 \%)$ \\
\hline & Molecular weight (Da) & $364.99 \pm 100.13$ & $358.24 \pm 105.13$ & $373.63 \pm 98.27$ & $332.45 \pm 54.27$ & $374.39 \pm 50.93$ \\
\hline & $\mathrm{O}: \mathrm{C}$ & $0.433 \pm 0.14$ & $0.377 \pm 0.11$ & $0.480 \pm 0.14$ & $0.405 \pm 0.11$ & $0.652 \pm 0.17$ \\
\hline & $\mathrm{H}: \mathrm{C}$ & $1.13 \pm 0.32$ & $1.12 \pm 0.30$ & $1.04 \pm 0.22$ & $1.96 \pm 0.10$ & $1.77 \pm 0.14$ \\
\hline & $\mathrm{OS}_{\mathrm{C}}$ & $-0.471 \pm 0.41$ & $-0.368 \pm 0.38$ & $-0.461 \pm 0.28$ & $-1.578 \pm 0.22$ & $-1.303 \pm 0.21$ \\
\hline & $\mathrm{DBE}$ & $9.26 \pm 3.94$ & $9.42 \pm 4.03$ & $9.99 \pm 3.11$ & $1.31 \pm 0.64$ & $3.08 \pm 0.9$ \\
\hline & $\mathrm{AI}_{\text {mod }}$ & $0.36 \pm 0.20$ & $0.38 \pm 0.19$ & $0.39 \pm 0.18$ & $0.00 \pm 0.00$ & $0.00 \pm 0.00$ \\
\hline & $\mathrm{C}_{n}$ & $18.0 \pm 5.6$ & $18.9 \pm 5.7$ & $17.6 \pm 5.5$ & $15.0 \pm 3.5$ & $13.9 \pm 3.4$ \\
\hline & $\mathrm{O}_{n}$ & $7.5 \pm 2.4$ & $7.0 \pm 2.5$ & $8.1 \pm 2.3$ & $5.8 \pm 0.9$ & $8.6 \pm 0.7$ \\
\hline \multirow[t]{9}{*}{ BO0213D } & Number & 2753 & $1097(40 \%)$ & $1123(41 \%)$ & $249(9 \%)$ & $284(10 \%)$ \\
\hline & Molecular weight (Da) & $361.82 \pm 96.19$ & $351.26 \pm 102.62$ & $360.99 \pm 94.43$ & $354.82 \pm 75.64$ & $412.02 \pm 76.3$ \\
\hline & $\mathrm{O}: \mathrm{C}$ & $0.498 \pm 0.19$ & $0.424 \pm 0.15$ & $0.555 \pm 0.18$ & $0.435 \pm 0.16$ & $0.617 \pm 0.21$ \\
\hline & $\mathrm{H}: \mathrm{C}$ & $1.37 \pm 0.37$ & $1.25 \pm 0.34$ & $1.26 \pm 0.27$ & $1.9 \pm 0.22$ & $1.8 \pm 0.18$ \\
\hline & $\mathrm{OS}_{\mathrm{C}}$ & $-0.683 \pm 0.53$ & $-0.399 \pm 0.46$ & $-0.631 \pm 0.34$ & $-1.445 \pm 0.37$ & $-1.322 \pm 0.30$ \\
\hline & DBE & $6.64 \pm 3.65$ & $7.81 \pm 3.88$ & $7.44 \pm 2.6$ & $1.8 \pm 1.43$ & $3.19 \pm 1.47$ \\
\hline & $\mathrm{AI}_{\text {mod }}$ & $0.21 \pm 0.21$ & $0.29 \pm 0.21$ & $0.22 \pm 0.20$ & $0.01 \pm 0.06$ & $0.00 \pm 0.00$ \\
\hline & $\mathrm{C}_{n}$ & $16.7 \pm 5.3$ & $17.9 \pm 5.7$ & $15.8 \pm 4.9$ & $16 \pm 4.9$ & $16 \pm 4.7$ \\
\hline & $\mathrm{O}_{n}$ & $7.8 \pm 2.5$ & $7.2 \pm 2.4$ & $8.3 \pm 2.5$ & $6.3 \pm 1.4$ & $9.1 \pm 1.6$ \\
\hline
\end{tabular}

fates. These compound classes can be inferred from the analytical bias of the negative mode ESI, as well as the $\mathrm{O}: \mathrm{N}$ and $\mathrm{O}: \mathrm{S}$ of the assigned molecular formulas. Nearly all $\mathrm{N}$ containing formulas had $\mathrm{O}: \mathrm{N}>3$, suggesting that the majority of the nitrogen species contained at least one nitro or nitrate group. Multiple nitrogen species, such as those of classes $\mathrm{N}_{2} \mathrm{O}_{3-5}$ and $\mathrm{N}_{3} \mathrm{O}_{5-7}$, have an $\mathrm{O}: \mathrm{N}$ low enough to indicate amine, imine, or imidazole structures, as these types of products have been reported in cloud water mimic reactions (De Haan et al., 2011); however only a modest number of formulas with multiple nitrogen atoms were observed. All of the S-containing formulas had $\mathrm{O}: \mathrm{S}>4$ ratios, suggesting sulfite, sulfate, and sulfonic acid functionalities. These infer- ences are consistent with the ionization polarity, where oxidized and acidic components are more efficiently ionized in negative-ion ESI. A study by LeClair et al. (2012) - who performed FT-ICR MS/MS using negative mode ESI on a variety of CHNO, CHOS, and CHNOS components - confirmed that the studied compounds in Fresno fog were indeed multifunctional organonitrates, organosulfates, and nitrooxy organosulfates. Furthermore, nitrate and sulfate salts are common secondary components present in the Po Valley (Giulianelli et al., 2014), and reactions between these inorganic salts and organics are expected as secondary reactions in the aqueous phase (Noziere et al., 2010; McNeill et al., 2012; Herrmann et al., 2015; McNeill, 2015). Amines have 

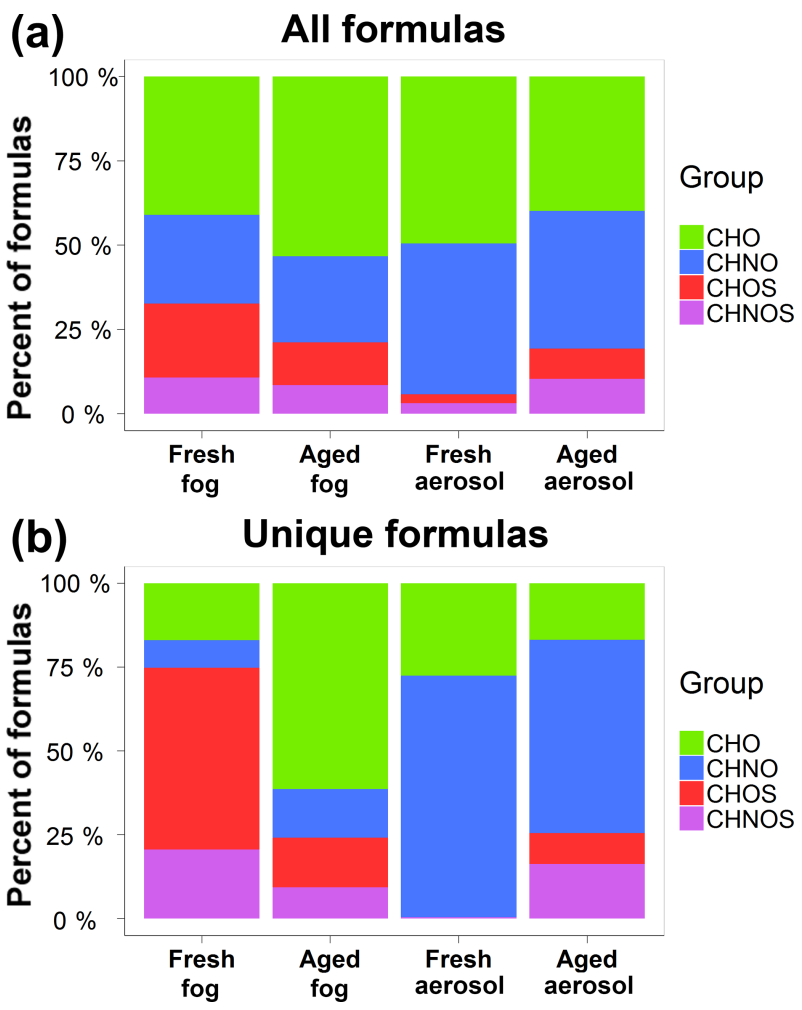

Figure 3. Percentage of assigned molecular formulas to each of the elemental groups in the Po Valley samples, where (a) includes all identified molecular formulas and (b) includes only the unique molecular formulas. The sample names fresh fog, aged fog, fresh aerosol, and aged aerosol correspond to SPC0106F, SPC0201F, BO0204N, and BO0213D, respectively.

been observed in the Po Valley, emitted by livestock farming and waste treatment activity, and it is possible that some species with amine groups were emitted from smoldering biomass combustion (Andreae and Merlet, 2001; Paglione et al., 2014). However, given the analytical bias for acidic functional groups in the ESI negative-ion mode, it is unlikely that reduced nitrogen species were detected. Nitrated phenols are known contributors to light-absorbing atmospheric brown carbon and are associated with biomass burning (Desyaterik et al., 2013; Laskin et al., 2015). In this work, a large number of CHNO formulas were observed with low $\mathrm{H}: \mathrm{C}$ and low $\mathrm{O}: \mathrm{C}$, especially in the fresh aerosol and fresh fog samples (Fig. S2); several of the CHNO formulas were also estimated to be aromatic using the $\mathrm{AI}_{\text {mod }}$ calculation (Fig. 4). Specifically, the molecular formulas for nitrophenol, methylnitrophenol, dinitrophenol, nitroguaiacol, and nitrosalicylic acid (Kitanovski et al., 2012; Desyaterik et al., 2013) were observed in all four Po Valley samples (Table S1 in the Supplement).

All of the molecular formulas were plotted in van Krevelen space ( $\mathrm{H}: \mathrm{C}$ vs. $\mathrm{O}: \mathrm{C})$ partitioned by sample (columns) and elemental group (rows) (Figs. 5, S2). In this space, molecu-

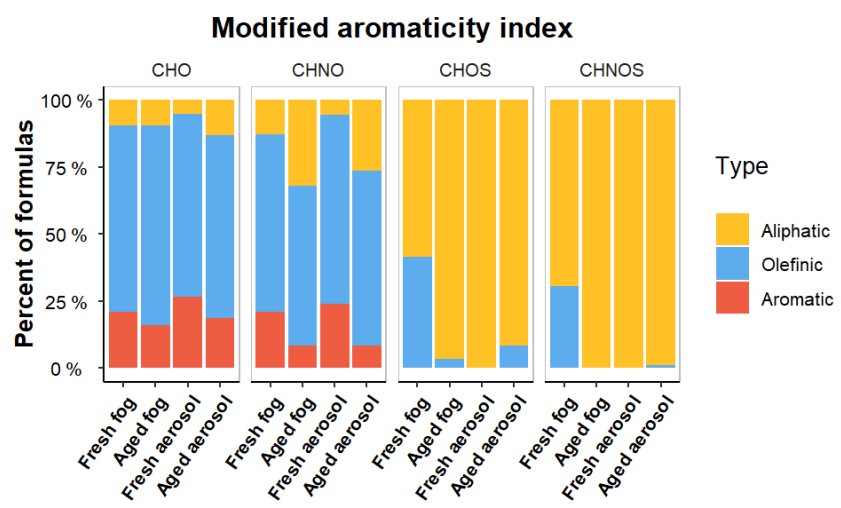

Figure 4. The modified aromaticity index $\left(\mathrm{AI}_{\mathrm{mod}}\right)$ for the assigned molecular formulas (Eqs. 5-7) and the percentage of each $\mathrm{AI}_{\text {mod }}$ type, as defined by Koch and Dittmar (2016): aliphatic $\left(\mathrm{AI}_{\bmod }=0\right)$, olefinic $\left(0<\mathrm{AI}_{\text {mod }} \leq 0.5\right)$, aromatic $\left(\mathrm{AI}_{\text {mod }}>0.5\right)$, and condensed aromatic $\left(\mathrm{AI}_{\bmod } \geq 0.67\right)$. Here aromatic and condensed aromatic formulas were combined, because a small fraction of condensed aromatics was observed. The results are partitioned by elemental group, where it can be seen that the majority of olefinic and aromatic compounds belong to the $\mathrm{CHO}$ and $\mathrm{CHNO}$ groups. The sample names fresh fog, aged fog, fresh aerosol, and aged aerosol correspond to SPC0106F, SPC0201F, BO0204N, and BO0213D, respectively.

lar formulas with $\mathrm{O}: \mathrm{C} \geq 0.6$ and $\mathrm{OS}_{\mathrm{C}} \geq 0$ are considered to be highly oxidized, and formulas with $\mathrm{H}: \mathrm{C} \geq 1.2$ are considered to be highly saturated (Tu et al., 2016). The distribution of the CHO and CHNO formulas is quite similar to WSOC extracted from ambient fog collected in Fresno, CA, USA (Mazzoleni et al., 2010). Additionally, the distribution of $\mathrm{CHO}$ formulas from phenolic aqueous SOA reported in Yu et al. (2016) partially covers the same area of the van Krevelen space. The CHOS and CHNOS formulas with high $\mathrm{H}$ : C ratios were also distributed similarly to Mazzoleni et al. (2010). The high $\mathrm{H}: \mathrm{C}$ ratios indicate that the majority of the CHOS and CHNOS formulas represent aliphatic organosulfate compounds, consistent with the aliphatic $\mathrm{AI}_{\text {mod }}$ values (Fig. 4). In contrast, the majority of the formulas with aromatic $\mathrm{AI}_{\text {mod }}$ values were in the $\mathrm{CHO}$ and $\mathrm{CHNO}$ groups, and tended to cluster at low $\mathrm{H}: \mathrm{C}$ and low $\mathrm{O}: \mathrm{C}$ in the van Krevelen space, in agreement with previous studies (Mazzoleni et al., 2010; LeClair et al., 2012). Consistent with the ${ }^{1} \mathrm{H}-\mathrm{NMR}$ results in Fig. 1b, the van Krevelen diagrams for SPC0106F and BO0213D were similar (see also Fig. S2), barring the additional low-H : C CHOS and CHNOS formulas of SPC0106F and the additional CHNO formulas of BO0213D.

Underscoring the influence of biomass burning on these samples, we found several molecular formulas matching previously observed species in biomass-burning-influenced ambient cloud water from Mt. Tai, China (Desyaterik et al., 2013). There were also several matches with the products of laboratory phenolic aqueous SOA reactions (Yu et al., 2014, 2016) (Table S1). Other notable molecular formulas included 


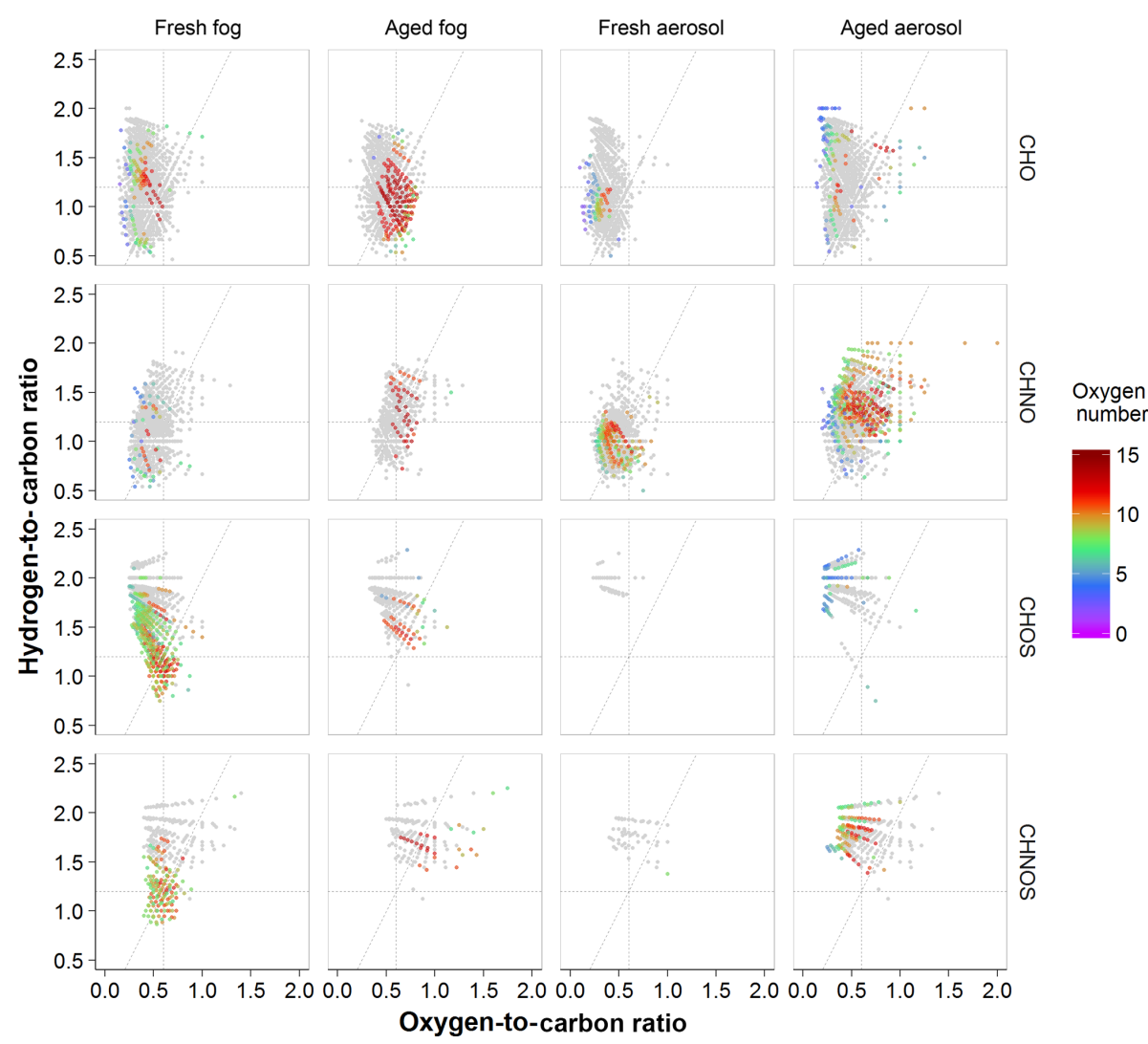

Figure 5. Van Krevelen diagrams for the SPE-recovered WSOC by elemental group (rows) and sample (columns) as indicated in the figure. Dashed lines represent $\mathrm{H}: \mathrm{C}=1.2$ (horizontal), $\mathrm{O}: \mathrm{C}=0.6$ (vertical), and $\mathrm{OS}_{\mathrm{C}}=0$ (diagonal) as described in Tu et al. (2016). Formulas unique to each sample are color-scaled to the number of oxygen atoms in the assigned formula; grey points represent common molecular formula assignments. The sample names fresh fog, aged fog, fresh aerosol, and aged aerosol correspond to SPC0106F, SPC0201F, BO0204N, and BO0213D, respectively. A similar plot with all of the molecular formulas scaled to indicate the number of oxygen atoms is provided as Fig. S2.

those for the following compounds: acetosyringone, acetovanillone, azelaic acid, benzoic acid, coumaric acid, hydroxybenzoic acid, ketolimononaldehyde, nitrocatechol, o-toluic acid, phthalic acid, syringaldehyde, syringic acid, tyrosine, vanillic acid, and vanillin (Table S1) (Mazzoleni et al., 2007; Desyaterik et al., 2013; Nguyen et al., 2013; Pietrogrande et al., 2014a, b, 2015; Yu et al., 2014, 2016; Dzepina et al., 2015). The molecular formulas for common methoxyphenols (syringol $\left(\mathrm{C}_{8} \mathrm{H}_{10} \mathrm{O}_{3}\right)$, methylsyringol $\left(\mathrm{C}_{9} \mathrm{H}_{12} \mathrm{O}_{3}\right)$, and eugenol $\left.\left(\mathrm{C}_{10} \mathrm{H}_{12} \mathrm{O}_{2}\right)\right)$ were present in all samples except BO0204N; as they are both semi-volatile and water-soluble, they are not expected to be present in aerosol with low liquid water content. Several formulas were also found that could be more oxidized versions of phenolic species produced from biomass burning. These formulas included additional oxygen atoms added to the base formulas for phenol $\left(\mathrm{C}_{6} \mathrm{H}_{6} \mathrm{O}_{3-5}\right)$, guaiacol $\left(\mathrm{C}_{7} \mathrm{H}_{8} \mathrm{O}_{3-6}\right)$, and syringol $\left(\mathrm{C}_{8} \mathrm{H}_{10} \mathrm{O}_{4-7}\right)$. Five of these formulas $-\mathrm{C}_{6} \mathrm{H}_{6} \mathrm{O}_{3}, \mathrm{C}_{6} \mathrm{H}_{6} \mathrm{O}_{5}, \mathrm{C}_{8} \mathrm{H}_{10} \mathrm{O}_{5}, \mathrm{C}_{8} \mathrm{H}_{10} \mathrm{O}_{6}$, and $\mathrm{C}_{8} \mathrm{H}_{10} \mathrm{O}_{7}$ - were previously observed in biomass burning aerosol (Pietrogrande et al., 2015) and in the products of laboratory phenolic aqueous-phase SOA reactions (Yu et al., 2014, 2016).

\subsubsection{Molecular trends for the compositions of ambient fog and aerosol}

Molecular formula trend histograms are a useful way to organize and visualize the thousands of molecular formulas observed here. The trends based on carbon number, oxygen number, and DBE of the assigned molecular formulas are shown in Fig. 6. Although relative abundance does not directly correspond to analyte concentrations, it provides a basis for relative comparisons. For example, the influence of terpene SOA products is indicated from the elevated total relative abundance of molecular formulas near $\mathrm{C}_{10}$ (observed in all samples) and an additional increased abundance between $\mathrm{C}_{15}$ and $\mathrm{C}_{18}$ (observed in most samples). This was especially pronounced in BO0213D (Fig. 6a). These formulas are likely derived from monoterpenes $\left(\mathrm{C}_{10}\right)$ and sesquiterpenes $\left(C_{15}\right)$, where terpene emissions have been observed in biomass burning (Andreae and Merlet, 2001). Terpene ox- 

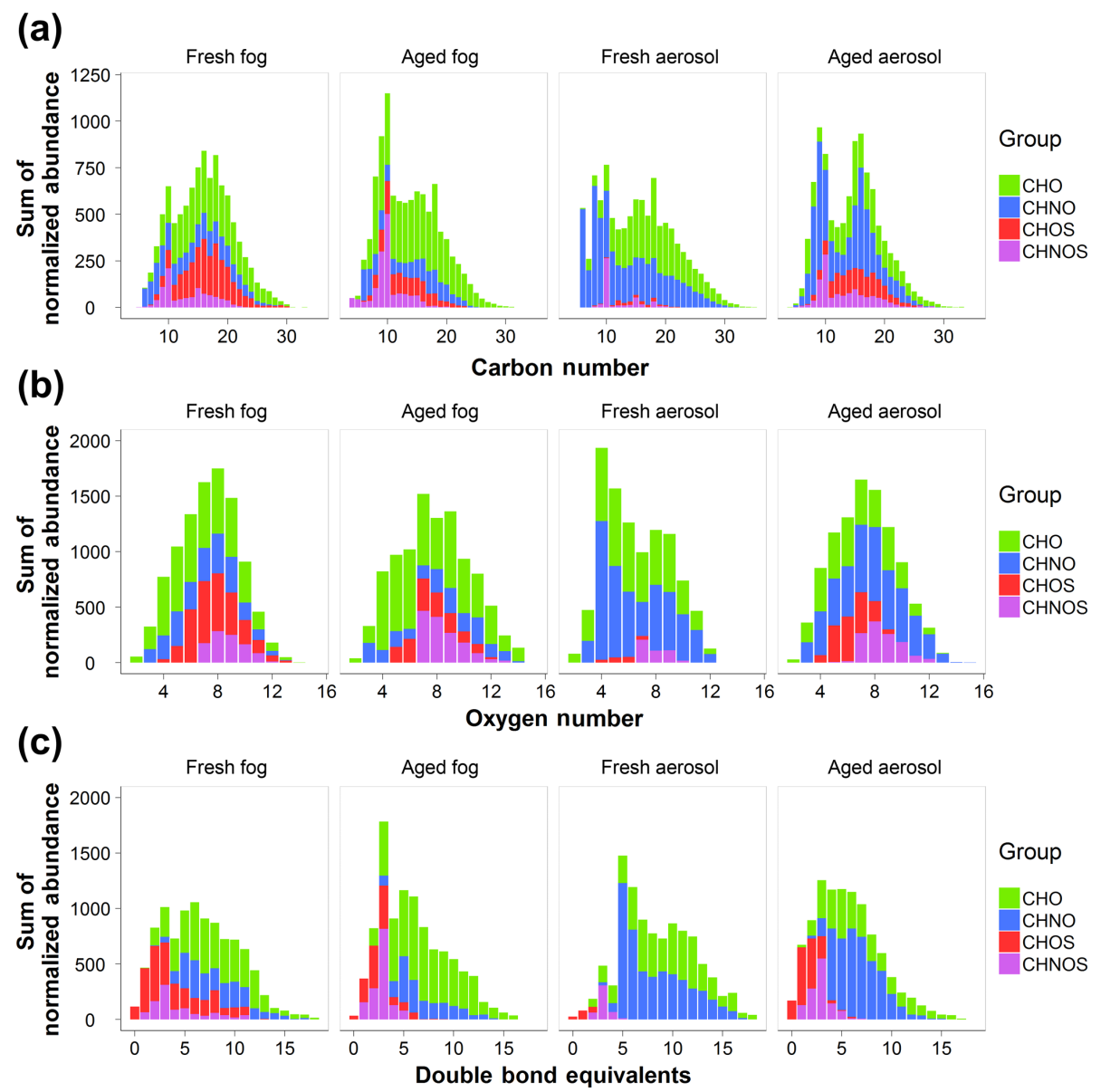

Figure 6. Molecular formula trends for carbon (a), oxygen (b), and the number of double-bond equivalents (c). All detected molecular formula abundances were normalized to the total assigned ion abundance for each sample and then summed across the integer values for carbon number, oxygen number, or double-bond equivalent values. The sample names fresh fog, aged fog, fresh aerosol, and aged aerosol correspond to SPC0106F, SPC0201F, BO0204N, and BO0213D, respectively.

idation products, including organosulfates, have previously been observed in biomass-burning-influenced cloud water (Cook et al., 2017; Zhao et al., 2013), and many of the same molecular formulas were observed in this study (Table S1). Specifically, we observed molecular formulas for pinic acid, ketopinic acid, pinonic acid, hydroxy-dimethylglutaric acid, and methyl-butanetricarboxylic acid (Table S1) (He et al., 2014). Overall, the trends indicate an enhanced abundance of CHO formulas in SPC0201F, CHNO formulas in BO0204N and BO0213D, and CHOS formulas in SPC0106F (Fig. 6a). Consistent with the ${ }^{1} \mathrm{H}$-NMR results in Fig. $1 b$, there is a strong similarity between samples SPC0106F and BO0213D, especially for the oxygen and DBE trends shown in Fig. 6b and $\mathrm{c}$.

Difference mass spectra were constructed from the assigned monoisotopic molecular formulas for the fog and aerosol samples (Fig. S3) and provide a direct comparison of their compositions. Each of the individual relative abundances was normalized by the total abundance of the as- signed masses for each sample. In Fig. S3, the individual masses with higher abundances in either the positive or negative direction were substantially greater in the fresh or aged samples, respectively; the masses with similar relative abundances tended to cancel each other. Overall, we observed molecular formulas with higher oxygen content at lower molecular weights in the two aged samples compared to the two fresh samples. To investigate this further, we adapted the approach used for the molecular formula trends described above with the difference relative abundances. The resulting difference trend plots are shown in Fig. 7 for carbon, and Figs. S4 and S5 for oxygen and DBE, respectively. In Fig. 7b, it is clear there was an enhanced abundance of CHOS and CHNOS formulas with higher carbon numbers in the fresh fog, while the aged fog showed an enhanced abundance of low-carbon-number CHO formulas. In Fig. 7a, it is clear that the fresh aerosol had an enhanced abundance of highercarbon-number formulas, though, unlike the fog samples, they were mainly $\mathrm{CHO}$ and $\mathrm{CHNO}$ compounds. The aged 

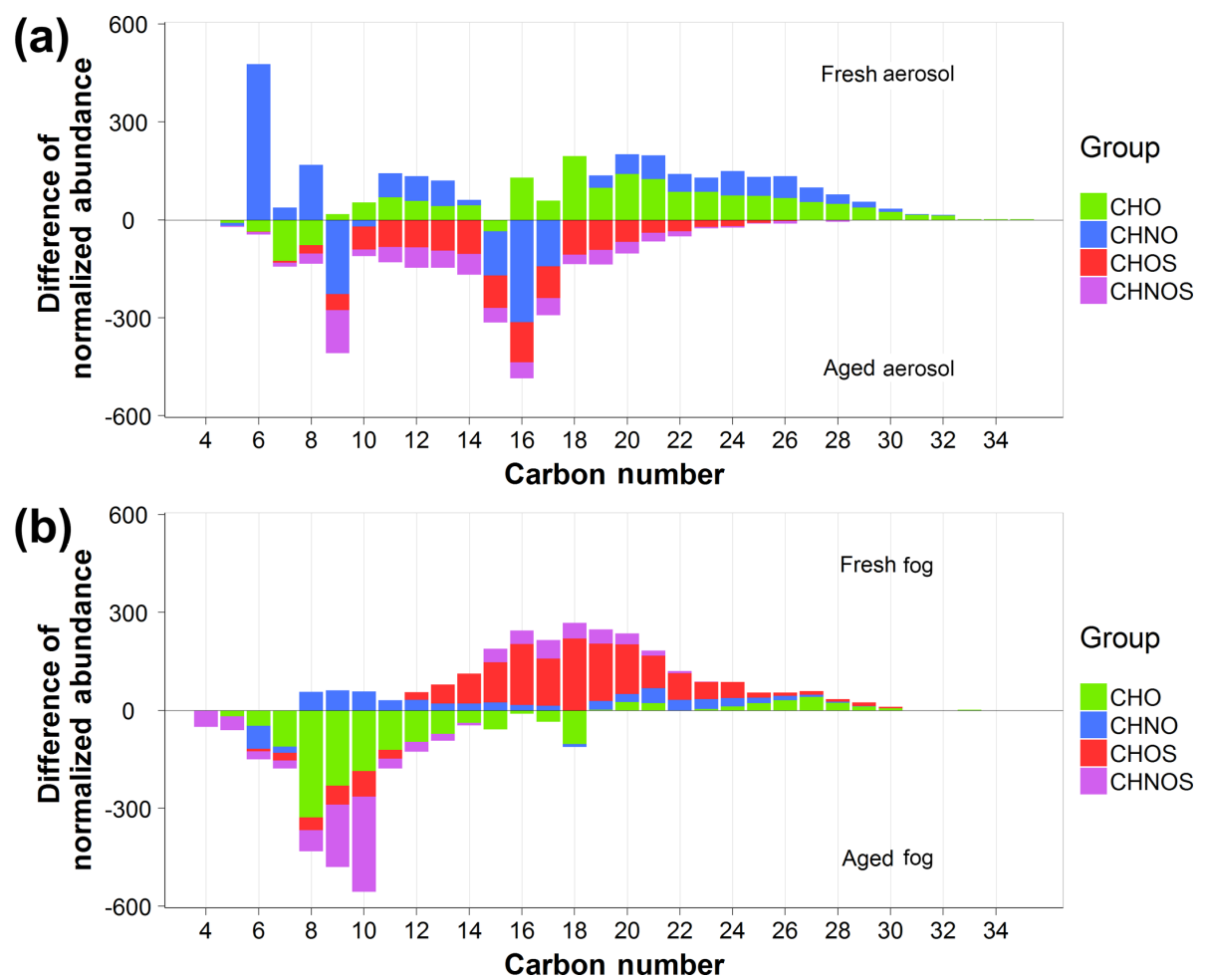

Figure 7. Carbon difference trend plots for aerosol (a) and fog (b) sample types. Difference trends were calculated as in Fig. 6, and then the respective aged sample was subtracted from the fresh sample for each integer carbon number value. Positive values indicate an enhanced abundance of the formulas in the fresh sample compared to the aged sample. Similarly, negative values indicate an enhanced abundance of formulas in the aged sample compared to the fresh sample. The sample names fresh fog, aged fog, fresh aerosol, and aged aerosol correspond to SPC0106F, SPC0201F, BO0204N, and BO0213D, respectively.

aerosol had an enhanced abundance of low-carbon-number formulas from the CHOS and CHNOS groups. In both fog and aerosol, there is an enhanced abundance of higher carbon numbers in the fresh samples relative to the aged samples. Overall, the carbon numbers are shifted to lower values in the fog compared to aerosol (Fig. 7), and the oxygen numbers are shifted to higher values in fog compared to aerosol (Fig. S4).

The subsequent sections discuss the molecular diversity of the different samples, especially considering the sample type, atmospheric processes during sample collection, and the unique molecular formulas observed in each sample. The distributions of unique molecular formulas are shown in Figs. $3 \mathrm{~b}$ and $\mathrm{S} 1$.

\subsubsection{Comparison of the fresh and aged biomass-burning-influenced fog compositions}

The molecular formulas of the aged biomass-burninginfluenced fog (SPC0201F) were more oxidized than the fresh biomass-burning-influenced fog (SPC0106F). This enhancement in oxidation is shown in Fig. S4a, with a greater abundance of higher-oxygen-number formulas observed in the aged fog. The opposite is true for DBE and carbon num- bers, where both trended to higher numbers in the fresh fog compared to the aged fog (see Figs. 7b and S5b). Most of the CHOS and CHNOS formulas in SPC0106F and SPC0201F were classified as aliphatic by $\mathrm{AI}_{\text {mod }}$, and approximately $30 \%$ of these formulas in SPC0106F were classified as olefinic, which was higher than any other sample (Fig. 4). This suggests that the fresh fog molecular formulas represented molecules with large unsaturated carbon backbones, which is consistent with pollutants without significant atmospheric aging. In contrast, the molecular formulas with smaller carbon backbones that were more oxidized were more prevalent in the aged fog.

The unique molecular formulas found in the fresh fog (SPC0106F) were mostly of the $\mathrm{O}_{5-13} \mathrm{~S}$ and $\mathrm{NO}_{7-12} \mathrm{~S}$ subclasses. Organosulfates are known products of aqueous secondary processes (Darer et al., 2011; Ervens et al., 2011; McNeill, 2015; Schindelka et al., 2013), and nucleation scavenging from the preceding fog nuclei composition likely plays a significant role as well (Darer et al., 2011; Gilardoni et al., 2014; Herckes et al., 2007; Hu et al., 2011). The aromatic organosulfates and nitooxy organosulfates observed in fresh biomass burning aerosol (Staudt et al., 2014) were not observed here. Organosulfates are the products of aqueousphase SOA reactions and are expected to be enhanced 
at acidic pH (Ervens et al., 2011; McNeill et al., 2012; Noziere et al., 2010). Because the pH of SPC0106F was only slightly acidic at 5.81 , we propose that the formation of these organosulfates may have been promoted by low LWC, and thus relatively high solute concentrations, during the activation of the fog droplets or possibly in the fully formed fog droplets. Organosulfates may also efficiently nucleate droplets, leading to their eventual presence in the fog samples. A noticeable number of CHOS and CHNOS formulas unique to SPC0106F had higher DBE values than formulas from other samples. There was an overall preference for CHOS and CHNOS formulas with DBE values $<6$, except for some of the formulas in SPC0106F which were higher (Fig. 6c). The 10 most abundant unique molecular formulas in the fresh biomass-burning-influenced fog of SPC0106F were all CHOS and CHNOS formulas: $\mathrm{C}_{11} \mathrm{H}_{15} \mathrm{NO}_{8} \mathrm{~S}$, $\mathrm{C}_{13} \mathrm{H}_{14} \mathrm{O}_{8} \mathrm{~S}, \quad \mathrm{C}_{14} \mathrm{H}_{16} \mathrm{O}_{8} \mathrm{~S}, \quad \mathrm{C}_{15} \mathrm{H}_{16} \mathrm{O}_{9} \mathrm{~S}, \quad \mathrm{C}_{15} \mathrm{H}_{24} \mathrm{O}_{7} \mathrm{~S}$, $\mathrm{C}_{15} \mathrm{H}_{24} \mathrm{O}_{8} \mathrm{~S}, \mathrm{C}_{16} \mathrm{H}_{18} \mathrm{O}_{9} \mathrm{~S}, \mathrm{C}_{17} \mathrm{H}_{20} \mathrm{O}_{9} \mathrm{~S}, \mathrm{C}_{18} \mathrm{H}_{30} \mathrm{O}_{8} \mathrm{~S}$, and $\mathrm{C}_{19} \mathrm{H}_{24} \mathrm{O}_{9} \mathrm{~S}$. These formulas may be tracer species for partially fog-processed biomass burning emissions.

While all samples contained some unique molecular formulas among the $\mathrm{CHO}$ subclasses, a high number of formulas in the $\mathrm{O}_{9-14}$ subclasses were unique to the aged fog (SPC0201F). This trend could indicate enhanced oxidation and aging as a result of aqueous-phase reactions in fog. The high average $\mathrm{O}: \mathrm{C}$ ratio $(0.577 \pm 0.18)$ and low $\mathrm{pH}$ (3.34) of SPC0201F are consistent with the trend observed by Cook et al. (2017) for cloud water, where the average $\mathrm{O}: \mathrm{C}$ increased with decreasing $\mathrm{pH}$. Overall, we observed a significant number of CHNO, CHOS, and CHNOS molecular formulas in SPC0201F, which are expected products of secondary aqueous-phase reactions in fog. However, there was a lower percentage of CHNO, CHOS, and CHNOS formulas, and an increased percentage of $\mathrm{CHO}$ formulas in SPC0201F compared to SPC0106F, suggesting that aqueous SOA products with $\mathrm{N}$ or $\mathrm{S}$ may have been transformed by acid hydrolysis into more stable CHO species (Darer et al., 2011). This is reasonable given the longer duration of the fog episode as well as the higher LWC of SPC0201F compared to SPC0106F. The increased oxidation is supported by the ${ }^{1} \mathrm{H}-$ NMR analysis, which showed an enrichment of carboxylic acids and other compounds carrying acyl groups. SPC0201F had additional unique formulas which were highly oxygenated in the $\mathrm{NO}_{13}, \mathrm{O}_{11} \mathrm{~S}$, and $\mathrm{NO}_{13} \mathrm{~S}$ subclasses, which appeared on the low mass end of the homologous series in the CHOS and CHNOS groups (Fig. S6). The 10 most abundant unique molecular formulas in the aged biomassburning-influenced fog (SPC0201F) were CHO, CHOS, and CHNOS species with smaller carbon skeletons than the fresh biomass-burning-influenced fog (SPC0106F), including $\mathrm{C}_{4} \mathrm{H}_{9} \mathrm{NO}_{7} \mathrm{~S}, \mathrm{C}_{5} \mathrm{H}_{9} \mathrm{NO}_{7} \mathrm{~S}, \mathrm{C}_{8} \mathrm{H}_{12} \mathrm{O}_{7} \mathrm{~S}, \mathrm{C}_{8} \mathrm{H}_{13} \mathrm{NO}_{11} \mathrm{~S}$, $\mathrm{C}_{8} \mathrm{H}_{14} \mathrm{O}_{7} \mathrm{~S}, \mathrm{C}_{9} \mathrm{H}_{16} \mathrm{O}_{8} \mathrm{~S}, \mathrm{C}_{10} \mathrm{H}_{10} \mathrm{O}_{7}, \mathrm{C}_{10} \mathrm{H}_{18} \mathrm{O}_{5} \mathrm{~S}, \mathrm{C}_{11} \mathrm{H}_{8} \mathrm{O}_{7}$, and $\mathrm{C}_{12} \mathrm{H}_{14} \mathrm{O}_{9}$. These formulas may be tracer species for heavily fog-processed biomass burning emissions.

\subsubsection{Comparison of the fresh and aged biomass-burning-influenced aerosol compositions}

Similar to the fog samples, the fresh aerosol formulas trended towards higher carbon and DBE numbers relative to the aged aerosol formulas. These carbon number and DBE trends are clearly visible through the difference trends shown in Figs. 7a and S6a, respectively. Both aerosol samples had a high percentage of formulas that contained nitrogen, with a noticeable number of $\mathrm{CHNO}$ formulas unique to these samples (Fig. 3b). This larger percentage of CHNO formulas may be attributed to enhanced $\mathrm{NO}_{X}$ concentrations associated with urban traffic emissions (Glasius et al., 2006) (Table 1). However, residential wood-combustion-influenced cloud water collected near Steamboat Springs, CO, USA, was found to be composed of $\sim 52 \%$ CHNO molecular formulas (Zhao et al., 2013), and elevated numbers of CHNO formulas were also reported in aerosol with a strong regional biomass burning influence (Schmitt-Kopplin et al., 2010) and wildfireinfluenced cloud water (Cook et al., 2017).

The majority of the unique formulas in the fresh aerosol (BO0204N) were in the $\mathrm{NO}_{6-12}$ and $\mathrm{N}_{2} \mathrm{O}_{7-11}$ subclasses, which were expected to be products of $\mathrm{NO}_{X}$ reactions and nighttime nitrate radical reactions. The formulas of BO0204N were less saturated and less oxygenated compared to the formulas in the aged aerosol (BO0213D), which would be expected with little to no influence from aqueous-phase secondary processes in the dry conditions of BO0204N (Ervens et al., 2011; McNeill, 2015). This could also help to explain the low percentage of CHOS and CHNOS formulas observed in BO0204N. Overall, no unique CHOS formulas were detected in BO0204N, and only one unique CHNOS formula $\left(\mathrm{C}_{8} \mathrm{H}_{11} \mathrm{NO}_{8} \mathrm{~S}\right)$ was detected. The small number of observed CHOS and CHNOS formulas in BO0204N may have originated from the increase in LWC (up to $\sim 300 \mu \mathrm{g} \mathrm{m}^{-3}$ ) observed in the last $4 \mathrm{~h}$ of sample collection and thus may have been formed by processes similar to those in BO0213D. DBE values in BO0204N trended towards values up to 10 , which was much higher than in other samples, where the trend stopped near DBE of 5 (Fig. 6c). The 10 most abundant unique molecular formulas in the aerosol with a fresh biomass burning influence (BO0204N) were mostly $\mathrm{N}_{1}$ and $\mathrm{N}_{2}$ CHNO formulas: $\mathrm{C}_{8} \mathrm{H}_{4} \mathrm{~N}_{2} \mathrm{O}_{6}$, $\mathrm{C}_{12} \mathrm{H}_{10} \mathrm{~N}_{2} \mathrm{O}_{8}, \mathrm{C}_{13} \mathrm{H}_{12} \mathrm{~N}_{2} \mathrm{O}_{8}, \mathrm{C}_{15} \mathrm{H}_{14} \mathrm{~N}_{2} \mathrm{O}_{10}, \mathrm{C}_{16} \mathrm{H}_{15} \mathrm{NO}_{6}$, $\mathrm{C}_{17} \mathrm{H}_{20} \mathrm{O}_{5}, \mathrm{C}_{20} \mathrm{H}_{18} \mathrm{O}_{8}, \mathrm{C}_{24} \mathrm{H}_{21} \mathrm{NO}_{10}, \mathrm{C}_{24} \mathrm{H}_{23} \mathrm{NO}_{10}$, and $\mathrm{C}_{26} \mathrm{H}_{23} \mathrm{NO}_{10}$. These formulas may be tracer species for biomass burning emissions when nighttime gas-phase reactions are dominant.

Several unique molecular formulas for the aged aerosol (BO0213D) were found in the $\mathrm{N}_{2} \mathrm{O}_{4-13}$ and $\mathrm{N}_{3} \mathrm{O}_{5-13}$ subclasses, as well as the $\mathrm{O}_{4-7} \mathrm{~S}, \mathrm{NO}_{5-7} \mathrm{~S}$, and $\mathrm{NO}_{10-12} \mathrm{~S}$ subclasses. A large fraction of the $\mathrm{N}_{2}$ formulas, and all of the $\mathrm{N}_{3}$ formulas, were unique to BO0213D. Compared to the other samples, BO0213D was collected during relatively high $\mathrm{NO}_{X}$ conditions, as well as high humidity and aerosol 
liquid water content compared to the other aerosol sample. The increased frequency of CHOS and CHNOS formulas in BO0213D compared to BO0204N was likely from reactions in the aqueous phase, enhanced by the increased concentration of species in aerosol liquid water (Darer et al., 2011; Hu et al., 2011; McNeill et al., 2012). Accretion reactions such as aldol condensation, acetal, and hemiacetal reactions are also expected to take place at a significant rate in these enhanced concentrations (Herrmann et al., 2015). While there was not a significant trend towards higher masses in BO0213D compared to other samples, the unique molecular formulas of this sample tended to fall on the highmass end of the homologous series, especially for CHNOS formulas (Fig. S6). The 10 most abundant unique molecular formulas for BO0213D were mostly highly oxygenated CHNO formulas: $\mathrm{C}_{7} \mathrm{H}_{9} \mathrm{NO}_{3}, \mathrm{C}_{9} \mathrm{H}_{15} \mathrm{NO}_{10}, \mathrm{C}_{12} \mathrm{H}_{25} \mathrm{NO}_{8} \mathrm{~S}$, $\mathrm{C}_{15} \mathrm{H}_{24} \mathrm{O}_{12}, \mathrm{C}_{16} \mathrm{H}_{18} \mathrm{~N}_{2} \mathrm{O}_{11}, \mathrm{C}_{16} \mathrm{H}_{20} \mathrm{~N}_{2} \mathrm{O}_{11}, \mathrm{C}_{17} \mathrm{H}_{22} \mathrm{~N}_{2} \mathrm{O}_{11}$, $\mathrm{C}_{17} \mathrm{H}_{22} \mathrm{~N}_{2} \mathrm{O}_{13}, \mathrm{C}_{18} \mathrm{H}_{21} \mathrm{~N}_{3} \mathrm{O}_{11}$, and $\mathrm{C}_{18} \mathrm{H}_{24} \mathrm{~N}_{2} \mathrm{O}_{11}$. These formulas may be tracer species for biomass burning emissions heavily aged by reactions in aerosol liquid water with photolysis.

\section{Summary and implications}

Hygroscopic species are expected to enhance droplet formation, indicating that organics acting as fog nuclei must be somewhat aged. In fog or wet aerosol, the water-soluble organics are subjected to further transformation in the aqueous phase, as we have observed here. These transformation processes in fog and aerosol water were shown to produce oxygenated and oxidized molecular formulas, as well as $\mathrm{N}$ containing and S-containing formulas with what were likely nitrate and sulfate functional groups. On the basis of the analysis of the selected aerosol and fog samples, representing extreme cases in the HR-ToF-AMS and ${ }^{1} \mathrm{H}-\mathrm{NMR}$ projections of the organic aerosol structural space, we can summarize the following observations.

An overall molecular trend was observed for both fog and aerosol samples, of concurrent shifts from lower $\mathrm{H}: \mathrm{C}$ and $\mathrm{O}: \mathrm{C}$ in samples with fresh biomass burning influence, and toward higher $\mathrm{H}: \mathrm{C}$ and $\mathrm{O}: \mathrm{C}$ values in samples with aged biomass burning influence. This was consistent with the ${ }^{1} \mathrm{H}-\mathrm{NMR}$ functional group distributions, which showed a decrease of aromatic moieties from the fresh to the aged aerosol, largely due to the disappearance of phenolic structures. The lower number of carbon atoms observed in aged samples suggests that the secondary formation of oligomers was somewhat counterbalanced by fragmentation reactions and/or by the uptake of low-molecular-weight compounds from the gas phase.

Overall, the fog composition was generally more oxidized and SOA-like than the aerosol, where the fresh fog composition was similar to the aged aerosol composition in both the ${ }^{1} \mathrm{H}-\mathrm{NMR}$ analysis and the molecular formula trends.
CHOS and CHNOS formulas were detected with high frequencies in samples with high water content during collection (all samples except BO0204N). This supports an enhanced production of $\mathrm{S}$-containing SOA species via reactions in the aqueous phase.

When the unique formulas of the two aged samples (SPC0201F and BO0213D) were compared, aging reactions in aerosol liquid water appeared to produce less highly oxygenated $\mathrm{CHO}$ formulas than in fog and a greater number of formulas in the CHNO, CHOS, and CHNOS groups. This difference could be explained by the increased chance of reactions with inorganic nitrate and sulfate ions in the relatively higher solute concentrations of aerosol liquid water compared to the increased likelihood of hydration reactions in fog (Darer et al., 2011; Hu et al., 2011). This conclusion agrees with the quantitative analysis of functional group composition of aqueous SOA isolated by PMF analysis reported previously (Gilardoni et al., 2016).

The variability of ${ }^{1} \mathrm{H}-\mathrm{NMR}$ fingerprints between samples reflects the change in oxidation state of the $\mathrm{CHO}$ family detected by FT-ICR MS (reaching a maximum for SPC0201F) but seems rather insensitive to the changes in content of heteroatom-containing groups (CHNO, CHOS, CHNOS). In fact, the formation of CHOS compounds detected in the FTICR MS analysis in deliquesced aerosols (BO0213D) or in low-LWC fog water (SPC0106F) could not be traced to parallel changes in ${ }^{1} \mathrm{H}-\mathrm{NMR}$ spectral characteristics. It is possible, however, that a fraction of the ${ }^{1} \mathrm{H}$-NMR-detected alkoxyl groups $(\mathrm{HCO})$ were bound to sulfate esters and misclassified as alcohols.

Compared to fresh fog (SPC0106F), the aged fog (SPC0201F) had an enhancement in the highly oxidized $\mathrm{CHO}$ formulas and an overall lower percentage of $\mathrm{CHNO}$ and CHOS formulas. This is likely due to hydrolysis reactions in the low-pH environment (Darer et al., 2011; Hu et al., 2011). The ${ }^{1} \mathrm{H}-\mathrm{NMR}$ analysis also highlighted that SPC0201F included highly oxidized low-molecular-weight organic acids (phthalic, maleic, succinic, pyruvic acids) which originated from the degradation of particulate WSOC, the oxidation of condensable water-soluble volatile organic compounds, and the uptake of condensable products of gasphase oxidative reactions.

In this work, we used the detailed molecular composition to describe the differences in aging and aqueous-phase processes for a select set of samples from the Supersito winter 2013 campaign. The majority of the molecular formulas observed in this study have not been previously reported but correlate with anticipated molecular trends. This emphasizes the importance of detailed molecular analysis of atmospheric samples, for the study of biomass burning emissions processed in the aqueous phase of aerosol and fog, as well as the potential of aqueous-phase processing to act as a source of SOA in the atmosphere. 
Data availability. An abbreviated list of the complete FT-ICR MS data set is provided and is available on Digital Commons: http: //digitalcommons.mtu.edu/chemistry-fp/98/ (Brege and Mazzoleni, 2018).

\section{The Supplement related to this article is available online at https://doi.org/10.5194/acp-18-13197-2018- supplement.}

Author contributions. This study was designed by SG, SD, MP, MCF, and LM. HR-ToF-MS, 1HNMR, and PMF analyses were done by SG, SD, and MP. FT-ICR MS analysis was done by MB and LM. All authors wrote the manuscript.

Competing interests. The authors declare that they have no conflict of interest.

Acknowledgements. This research was supported with a NASA Earth and Space Science Fellowship for Matthew Brege. The Italian CNR contribution was supported by the BACCHUS project, European Commission FP7-603445. The authors thank Melissa Soule and Elizabeth Kujawinski of the Woods Hole Oceanographic Institution (WHOI) Mass Spectrometry Facility for instrument time and assistance with data FT-ICR MS acquisition (NSF OCE-0619608 and Gordon and Betty Moore Foundation).

Edited by: Christopher Hoyle

Reviewed by: two anonymous referees

\section{References}

Aiken, A. C., Decarlo, P. F., Kroll, J. H., Worsnop, D. R., Huffman, J. A., Docherty, K. S., Ulbrich, I. M., Mohr, C., Kimmel, J. R., Sueper, D., Sun, Y., Zhang, Q., Trimborn, A., Northway, M., Ziemann, P. J., Canagaratna, M. R., Onasch, T. B., Alfarra, M. R., Prevot, A. S. H., Dommen, J., Duplissy, J., Metzger, A., Baltensperger, U., and Jimenez, J. L.: O / C and OM / OC ratios of primary, secondary, and ambient organic aerosols with high-resolution time-of-flight aerosol mass spectrometry, Environ. Sci. Technol., 42, 4478-4485, 2008.

Andreae, M. O. and Merlet, P.: Emission of trace gases and aerosols from biomass burning, Global Biogeochem. Cy., 15, 955-966, 2001.

Bond, T. C., Streets, D. G., Yarber, K. F., Nelson, S. M., Woo, J. H., and Klimont, Z.: A technology-based global inventory of black and organic carbon emissions from combustion, J. Geophys. Res.-Atmos., 109, D14203, https://doi.org/10.1029/2003JD003697, 2004.

Boone, E. J., Laskin, A., Laskin, J., Wirth, C., Shepson, P. B., Stirm, B. H., and Pratt, K. A.: Aqueous Processing of Atmospheric Organic Particles in Cloud Water Collected via Aircraft Sampling, Environ. Sci. Technol., 49, 8523-8530, 2015.

Brege, M. and Mazzoleni, L. R.: Ultrahigh resolution FT-ICR MS data for biomass burning emissions-influenced fog and aerosol from the Po Valley, available at: http://digitalcommons.mtu.edu/ chemistry-fp/98/, last access: 5 September 2018.

Chang, J. L. and Thompson, J. E.: Characterization of colored products formed during irradiation of aqueous solutions containing $\mathrm{H}_{2} \mathrm{O}_{2}$ and phenolic compounds, Atmos. Environ., 44, 541-551, 2010.

Cook, R. D., Lin, Y. H., Peng, Z. Y., Boone, E., Chu, R. K., Dukett, J. E., Gunsch, M. J., Zhang, W. L., Tolic, N., Laskin, A., and Pratt, K. A.: Biogenic, urban, and wildfire influences on the molecular composition of dissolved organic compounds in cloud water, Atmos. Chem. Phys., 17, 15167-15180, https://doi.org/10.5194/acp-17-15167-2017, 2017.

Cubison, M. J., Ortega, A. M., Hayes, P. L., Farmer, D. K., Day, D., Lechner, M. J., Brune, W. H., Apel, E., Diskin, G. S., Fisher, J. A., Fuelberg, H. E., Hecobian, A., Knapp, D. J., Mikoviny, T., Riemer, D., Sachse, G. W., Sessions, W., Weber, R. J., Weinheimer, A. J., Wisthaler, A., and Jimenez, J. L.: Effects of aging on organic aerosol from open biomass burning smoke in aircraft and laboratory studies, Atmos. Chem. Phys., 11, 12049-12064, https://doi.org/10.5194/acp-11-12049-2011, 2011.

Dall'Osto, M., Paglione, M., Decesari, S., Facchini, M. C., O'Dowd, C., Plass-Duellmer, C., and Harrison, R. M.: On the Origin of AMS "Cooking Organic Aerosol” at a Rural Site, Environ. Sci. Technol., 49, 13964-13972, 2015.

Darer, A. I., Cole-Filipiak, N. C., O'Connor, A. E., and Elrod, M. J.: Formation and Stability of Atmospherically Relevant IsopreneDerived Organosulfates and Organonitrates, Environ. Sci. Technol., 45, 1895-1902, 2011.

De Haan, D. O., Hawkins, L. N., Kononenko, J. A., Turley, J. J., Corrigan, A. L., Tolbert, M. A., and Jimenez, J. L.: Formation of Nitrogen-Containing Oligomers by Methylglyoxal and Amines in Simulated Evaporating Cloud Droplets, Environ. Sci. Technol., 45, 984-991, https://doi.org/10.1021/es102933x, 2011.

DeCarlo, P. F., Kimmel, J. R., Trimborn, A., Northway, M. J., Jayne, J. T., Aiken, A. C., Gonin, M., Fuhrer, K., Horvath, T., Docherty, K. S., Worsnop, D. R., and Jimenez, J. L.: Field-deployable, high-resolution, time-of-flight aerosol mass spectrometer, Anal. Chem., 78, 8281-8289, 2006.

Decesari, S., Facchini, M. C., Fuzzi, S., and Tagliavini, E.: Characterization of water-soluble organic compounds in atmospheric aerosol: A new approach, J. Geophys. Res.-Atmos., 105, 14811489, 2000.

Decesari, S., Mircea, M., Cavalli, F., Fuzzi, S., Moretti, F., Tagliavini, E., and Facchini, M. C.: Source attribution of water-soluble organic aerosol by nuclear magnetic resonance spectroscopy, Environ. Sci. Technol., 41, 2479-2484, 2007.

Desyaterik, Y., Sun, Y., Shen, X. H., Lee, T. Y., Wang, X. F., Wang, T., and Collett, J. L.: Speciation of "brown" carbon in cloud water impacted by agricultural biomass burning in eastern China, J. Geophys. Res.-Atmos., 118, 7389-7399, 2013.

Dzepina, K., Mazzoleni, C., Fialho, P., China, S., Zhang, B., Owen, R. C., Helmig, D., Hueber, J., Kumar, S., Perlinger, J. A., Kramer, L. J., Dziobak, M. P., Ampadu, M. T., Olsen, S., Wuebbles, D. J., and Mazzoleni, L. R.: Molecular characterization of free tropospheric aerosol collected at the Pico Mountain Observatory: a case study with a long-range transported biomass burning plume, Atmos. Chem. Phys., 15, 5047-5068, https://doi.org/10.5194/acp-15-5047-2015, 2015. 
Ervens, B., Turpin, B. J., and Weber, R. J.: Secondary organic aerosol formation in cloud droplets and aqueous particles (aqSOA): a review of laboratory, field and model studies, Atmos. Chem. Phys., 11, 11069-11102, https://doi.org/10.5194/acp-1111069-2011, 2011.

Fuzzi, S., Orsi, G., Bonforte, G., Zardini, B., and Franchini, P. L.: An automated fog water collector suitable for deposition networks: Design, operation and field tests, Water Air Soil Poll., 93, 383-394, 1997.

Gilardoni, S., Massoli, P., Giulianelli, L., Rinaldi, M., Paglione, M., Pollini, F., Lanconelli, C., Poluzzi, V., Carbone, S., Hillamo, R., Russell, L. M., Facchini, M. C., and Fuzzi, S.: Fog scavenging of organic and inorganic aerosol in the Po Valley, Atmos. Chem. Phys., 14, 6967-6981, https://doi.org/10.5194/acp14-6967-2014, 2014.

Gilardoni, S., Massoli, P., Paglione, M., Giulianelli, L., Carbone, C., Rinaldi, M., Decesari, S., Sandrini, S., Costabile, F., Gobbi, G. P., Pietrogrande, M. C., Visentin, M., Scotto, F., Fuzzi, S., and Facchini, M. C.: Direct observation of aqueous secondary organic aerosol from biomass-burning emissions, P. Natl. Acad. Sci. USA, 113, 10013-10018, 2016.

Giulianelli, L., Gilardoni, S., Tarozzi, L., Rinaldi, M., Decesari, S., Carbone, C., Facchini, M. C., and Fuzzi, S.: Fog occurrence and chemical composition in the Po valley over the last twenty years, Atmos. Environ., 98, 394-401, 2014.

Glasius, M., Ketzel, M., Wahlin, P., Jensen, B., Monster, J., Berkowicz, R., and Palmgren, F.: Impact of wood combustion on particle levels in a residential area in Denmark, Atmos. Environ., 40, 7115-7124, https://doi.org/10.1016/j.atmosenv.2006.06.047, 2006.

Hand, J. L., Malm, W. C., Laskin, A., Day, D., Lee, T., Wang, C., Carrico, C., Carrillo, J., Cowin, J. P., Collett, J., and Iedema, M. J.: Optical, physical, and chemical properties of tar balls observed during the Yosemite Aerosol Characterization Study, J. Geophys. Res.-Atmos., 110, D21210, https://doi.org/10.1029/2004JD005728, 2005.

Hawkins, L. N., Lemire, A. N., Galloway, M. M., Corrigan, A. L., Turley, J. J., Espelien, B. M., and De Haan, D. O.: Maillard Chemistry in Clouds and Aqueous Aerosol As a Source of Atmospheric Humic-Like Substances, Environ. Sci. Technol., 50, 7443-7452, https://doi.org/10.1021/acs.est.6b00909, 2016.

He, Q. F., Ding, X., Wang, X. M., Yu, J. Z., Fu, X. X., Liu, T. Y., Zhang, Z., Xue, J., Chen, D. H., Zhong, L. J., and Donahue, N. M.: Organosulfates from Pinene and Isoprene over the Pearl River Delta, South China: Seasonal Variation and Implication in Formation Mechanisms, Environ. Sci. Technol., 48, 9236-9245, 2014.

Herckes, P., Chang, H., Lee, T., and Collett, J. L.: Air pollution processing by radiation fogs, Water Air Soil Poll., 181, 65-75, https://doi.org/10.1007/s11270-006-9276-x, 2007.

Herckes, P., Valsaraj, K. T., and Collett, J. L.: A review of observations of organic matter in fogs and clouds: Origin, processing and fate, Atmos. Res., 132, 434-449, https://doi.org/10.1016/j.atmosres.2013.06.005, 2013.

Herrmann, H., Schaefer, T., Tilgner, A., Styler, S. A., Weller, C., Teich, M., and Otto, T.: Tropospheric Aqueous-Phase Chemistry: Kinetics, Mechanisms, and Its Coupling to a Changing Gas Phase, Chem. Rev., 115, 4259-4334, 2015.
Hertkorn, N., Ruecker, C., Meringer, M., Gugisch, R., Frommberger, M., Perdue, E. M., Witt, M., and Schmitt-Kopplin, P.: High-precision frequency measurements: indispensable tools at the core of the molecular-level analysis of complex systems, Anal. Bioanal. Chem., 389, 1311-1327, 2007.

Hu, K. S., Darer, A. I., and Elrod, M. J.: Thermodynamics and kinetics of the hydrolysis of atmospherically relevant organonitrates and organosulfates, Atmos. Chem. Phys., 11, 8307-8320, https://doi.org/10.5194/acp-11-8307-2011, 20

Kitanovski, Z., Grgic, I., Vermeylen, R., Claeys, M., and Maenhaut, W.: Liquid chromatography tandem mass spectrometry method for characterization of monoaromatic nitro-compounds in atmospheric particulate matter, J. Chromatogr. A, 1268, 35-43, https://doi.org/10.1016/j.chroma.2012.10.021, 2012.

Koch, B. P. and Dittmar, T.: From mass to structure: an aromaticity index for high-resolution mass data of natural organic matter, Rapid Commun. Mass. Sp., 20, 926-932, 2006.

Koch, B. P. and Dittmar, T.: From mass to structure: an aromaticity index for high-resolution mass data of natural organic matter (vol 20, pg 926, 2006), Rapid Commun. Mass. Sp., 30, 250-250, 2016.

Kroll, J. H., Donahue, N. M., Jimenez, J. L., Kessler, S. H., Canagaratna, M. R., Wilson, K. R., Altieri, K. E., Mazzoleni, L. R., Wozniak, A. S., Bluhm, H., Mysak, E. R., Smith, J. D., Kolb, C. E., and Worsnop, D. R.: Carbon oxidation state as a metric for describing the chemistry of atmospheric organic aerosol, Nat. Chem., 3, 133-139, 2011.

Larsen, B. R., Gilardoni, S., Stenstrom, K., Niedzialek, J., Jimenez, J., and Belis, C. A.: Sources for PM air pollution in the Po Plain, Italy: II. Probabilistic uncertainty characterization and sensitivity analysis of secondary and primary sources, Atmos. Environ., 50, 203-213, 2012.

Laskin, A., Laskin, J., and Nizkorodov, S. A.: Chemistry of Atmospheric Brown Carbon, Chem. Rev., 115, 4335-4382, 2015.

Laskin, A., Gilles, M. K., Knopf, D. A., Wang, B. B., and China, S.: Progress in the Analysis of Complex Atmospheric Particles, Annu. Rev. Anal. Chem., 9, 117-143, https://doi.org/10.1146/annurev-anchem-071015-041521, 2016.

LeClair, J. P., Collett, J. L., and Mazzoleni, L. R.: Fragmentation Analysis of Water-Soluble Atmospheric Organic Matter Using Ultrahigh-Resolution FT-ICR Mass Spectrometry, Environ. Sci. Technol., 46, 4312-4322, 2012.

Lee, A. K. Y., Hayden, K. L., Herckes, P., Leaitch, W. R., Liggio, J., Macdonald, A. M., and Abbatt, J. P. D.: Characterization of aerosol and cloud water at a mountain site during WACS 2010: secondary organic aerosol formation through oxidative cloud processing, Atmos. Chem. Phys., 12, 7103-7116, https://doi.org/10.5194/acp-12-7103-2012, 2012.

Lee, A. K. Y., Zhao, R., Li, R., Liggio, J., Li, S. M., and Abbatt, J. P. D.: Formation of Light Absorbing Organo-Nitrogen Species from Evaporation of Droplets Containing Glyoxal and Ammonium Sulfate, Environ. Sci. Technol., 47, 12819-12826, 2013.

Mazzoleni, L. R., Zielinska, B., and Moosmuller, H.: Emissions of levoglucosan, methoxy phenols, and organic acids from prescribed burns, laboratory combustion of wildland fuels, and residential wood combustion, Environ. Sci. Technol., 41, 21152122, 2007.

Mazzoleni, L. R., Ehrmann, B. M., Shen, X. H., Marshall, A. G., and Collett, J. L.: Water-Soluble Atmospheric Organic Mat- 
ter in Fog: Exact Masses and Chemical Formula Identification by Ultrahigh-Resolution Fourier Transform Ion Cyclotron Resonance Mass Spectrometry, Environ. Sci. Technol., 44, 36903697, 2010.

McNeill, V. F.: Aqueous Organic Chemistry in the Atmosphere: Sources and Chemical Processing of Organic Aerosols, Environ. Sci. Technol., 49, 1237-1244, https://doi.org/10.1021/es5043707, 2015.

McNeill, V. F., Woo, J. L., Kim, D. D., Schwier, A. N., Wannell, N. J., Sumner, A. J., and Barakat, J. M.: Aqueous-Phase Secondary Organic Aerosol and Organosulfate Formation in Atmospheric Aerosols: A Modeling Study, Environ. Sci. Technol., 46, 80758081, 2012.

Nguyen, T. B., Laskin, A., Laskin, J., and Nizkorodov, S. A.: Brown carbon formation from ketoaldehydes of biogenic monoterpenes, Faraday Discuss., 165, 473-494, 2013.

Nizkorodov, S. A., Laskin, J., and Laskin, A.: Molecular chemistry of organic aerosols through the application of high resolution mass spectrometry, Phys. Chem. Chem. Phys., 13, 3612-3629, 2011

Noziere, B., Ekstrom, S., Alsberg, T., and Holmstrom, S.: Radical-initiated formation of organosulfates and surfactants in atmospheric aerosols, Geophys. Res. Lett., 37, L05806, https://doi.org/10.1029/2009GL041683, 2010.

Noziere, B., Kaberer, M., Claeys, M., Allan, J., D’Anna, B., Decesari, S., Finessi, E., Glasius, M., Grgic, I., Hamilton, J. F., Hoffmann, T., Iinuma, Y., Jaoui, M., Kahno, A., Kampf, C. J., Kourtchev, I., Maenhaut, W., Marsden, N., Saarikoski, S., Schnelle-Kreis, J., Surratt, J. D., Szidat, S., Szmigielski, R., and Wisthaler, A.: The Molecular Identification of Organic Compounds in the Atmosphere: State of the Art and Challenges, Chem. Rev., 115, 3919-3983, https://doi.org/10.1021/cr5003485, 2015.

Paglione, M., Saarikoski, S., Carbone, S., Hillamo, R., Facchini, M. C., Finessi, E., Giulianelli, L., Carbone, C., Fuzzi, S., Moretti, F., Tagliavini, E., Swietlicki, E., Eriksson Stenström, K., Prévôt, A. S. H., Massoli, P., Canaragatna, M., Worsnop, D., and Decesari, S.: Primary and secondary biomass burning aerosols determined by proton nuclear magnetic resonance (1H-NMR) spectroscopy during the 2008 EUCAARI campaign in the Po Valley (Italy), Atmos. Chem. Phys., 14, 5089-5110, https://doi.org/10.5194/acp14-5089-2014, 2014.

Pietrogrande, M. C., Bacco, D., Visentin, M., Ferrari, S., and Casali, P.: Polar organic marker compounds in atmospheric aerosol in the Po Valley during the Supersito campaigns - Part 2: Seasonal variations of sugars, Atmos. Environ., 97, 215-225, 2014a.

Pietrogrande, M. C., Bacco, D., Visentin, M., Ferrari, S., and Poluzzi, V.: Polar organic marker compounds in atmospheric aerosol in the Po Valley during the Supersito campaigns - Part 1: Low molecular weight carboxylic acids in cold seasons, Atmos. Environ., 86, 164-175, 2014b.

Pietrogrande, M. C., Sacco, D., Ferrari, S., Kaipainen, J., Ricciardelli, I., Riekkola, M. L., Trentini, A., and Visentin, M.: Characterization of atmospheric aerosols in the Po valley during the supersito campaigns - Part 3: Contribution of wood combustion to wintertime atmospheric aerosols in Emilia Romagna region (Northern Italy), Atmos. Environ., 122, 291-305, 2015.

Poluzzi, V., Trentini, A., Scotto, F., Ricciardelli, I., Ferrari, S., Maccone, C., Bacco, D., Zigola, C., Bonafè, G., and Ugolini, P.: Pre- liminary results of the project "Supersito" concerning the atmospheric aerosol composition in Emilia-Romagna region, Italy: PM source apportionment and aerosol size distribution, WIT Transactions on The Built Environment, 168, 689-698, 2015.

Pratt, K. A., Fiddler, M. N., Shepson, P. B., Carlton, A. G., and Surratt, J. D.: Organosulfates in cloud water above the Ozarks' isoprene source region, Atmos. Environ., 77, 231-238, https://doi.org/10.1016/j.atmosenv.2013.05.011, 2013.

Putman, A. L., Offenberg, J. H., Fisseha, R., Kundu, S., Rahn, T. A., and Mazzoleni, L. R.: Ultrahigh-resolution FT-ICR mass spectrometry characterization of alpha-pinene ozonolysis SOA, Atmos. Environ., 46, 164-172, 2012.

Rinaldi, M., Emblico, L., Decesari, S., Fuzzi, S., Facchini, M. C., and Librando, V.: Chemical characterization and source apportionment of size-segregated aerosol collected at an urban site in sicily, Water Air Soil Poll., 185, 311-321, 2007.

Saarikoski, S., Carbone, S., Decesari, S., Giulianelli, L., Angelini, F., Canagaratna, M., Ng, N. L., Trimborn, A., Facchini, M. C., Fuzzi, S., Hillamo, R., and Worsnop, D.: Chemical characterization of springtime submicrometer aerosol in Po Valley, Italy, Atmos. Chem. Phys., 12, 8401-8421, https://doi.org/10.5194/acp12-8401-2012, 2012.

Schindelka, J., Iinuma, Y., Hoffmann, D., and Herrmann, H.: Sulfate radical-initiated formation of isoprene-derived organosulfates in atmospheric aerosols, Faraday Discuss., 165, 237-259, 2013.

Schmitt-Kopplin, P., Gelencser, A., Dabek-Zlotorzynska, E., Kiss, G., Hertkorn, N., Harir, M., Hong, Y., and Gebefugi, I.: Analysis of the Unresolved Organic Fraction in Atmospheric Aerosols with Ultrahigh-Resolution Mass Spectrometry and Nuclear Magnetic Resonance Spectroscopy: Organosulfates As Photochemical Smog Constituents, Anal. Chem., 82, 8017-8026, 2010.

Staudt, S., Kundu, S., Lehmler, H. J., He, X. R., Cui, T. Q., Lin, Y. H., Kristensen, K., Glasius, M., Zhang, X. L., Weber, R. J., Surratt, J. D., and Stone, E. A.: Aromatic organosulfates in atmospheric aerosols: Synthesis, characterization, and abundance, Atmos. Environ., 94, 366-373, 2014.

Stenson, A. C., Marshall, A. G., and Cooper, W. T.: Exact masses and chemical formulas of individual Suwannee River fulvic acids from ultrahigh resolution electrospray ionization Fourier transform ion cyclotron resonance mass spectra, Anal. Chem., 75, 1275-1284, 2003.

Surratt, J. D., Gomez-Gonzalez, Y., Chan, A. W. H., Vermeylen, R., Shahgholi, M., Kleindienst, T. E., Edney, E. O., Offenberg, J. H., Lewandowski, M., Jaoui, M., Maenhaut, W., Claeys, M., Flagan, R. C., and Seinfeld, J. H.: Organosulfate formation in biogenic secondary organic aerosol, J. Phys. Chem. A, 112, 8345-8378, 2008.

Suzuki, Y., Kawakami, M., and Akasaka, K.: H-1 NMR application for characterizing water-soluble organic compounds in urban atmospheric particles, Environ. Sci. Technol., 35, 2656-2664, 2001.

Tu, P. J., Hall, W. A., and Johnston, M. V.: Characterization of Highly Oxidized Molecules in Fresh and Aged Biogenic Secondary Organic Aerosol, Anal. Chem., 88, 4495-4501, 2016.

Willoughby, A. S., Wozniak, A. S., and Hatcher, P. G.: Detailed Source-Specific Molecular Composition of Ambient Aerosol Organic Matter Using Ultrahigh Resolution Mass Spectrometry and H-1 NMR, Atmosphere, 7, 79, https://doi.org/10.3390/atmos7060079, 2016. 
Xu, X., Chen, J., Zhu, C., Li, J., Sui, X., Liu, L., and Sun, J.: Fog composition along the Yangtze River basin: Detecting emission sources of pollutants in fog water, J. Environ. Sci.-China, 11, https://doi.org/10.1016/j.jes.2017.09.018, 2017.

Yu, L., Smith, J., Laskin, A., Anastasio, C., Laskin, J., and Zhang, Q.: Chemical characterization of SOA formed from aqueousphase reactions of phenols with the triplet excited state of carbonyl and hydroxyl radical, Atmos. Chem. Phys., 14, 1380113816, https://doi.org/10.5194/acp-14-13801-2014, 2014.

Yu, L., Smith, J., Laskin, A., George, K. M., Anastasio, C., Laskin, J., Dillner, A. M., and Zhang, Q.: Molecular transformations of phenolic SOA during photochemical aging in the aqueous phase: competition among oligomerization, functionalization, and fragmentation, Atmos. Chem. Phys., 16, 4511-4527, https://doi.org/10.5194/acp-16-4511-2016, 2016.

Zark, M., Christoffers, J., and Dittmar, T.: Molecular properties of deep-sea dissolved organic matter are predictable by the central limit theorem: Evidence from tandem FT-ICR-MS, Mar. Chem., 191, 9-15, 10.1016/j.marchem.2017.02.005, 2017.
Zhang, Q., Jimenez, J. L., Canagaratna, M. R., Allan, J. D., Coe, H., Ulbrich, I., Alfarra, M. R., Takami, A., Middlebrook, A. M., Sun, Y. L., Dzepina, K., Dunlea, E., Docherty, K., DeCarlo, P. F., Salcedo, D., Onasch, T., Jayne, J. T., Miyoshi, T., Shimono, A., Hatakeyama, S., Takegawa, N., Kondo, Y., Schneider, J., Drewnick, F., Borrmann, S., Weimer, S., Demerjian, K., Williams, P., Bower, K., Bahreini, R., Cottrell, L., Griffin, R. J., Rautiainen, J., Sun, J. Y., Zhang, Y. M., and Worsnop, D. R.: Ubiquity and dominance of oxygenated species in organic aerosols in anthropogenically-influenced Northern Hemisphere midlatitudes, Geophys. Res. Lett., 34, L13801, https://doi.org/10.1029/2007GL029979, 2007.

Zhang, Q., Jimenez, J. L., Canagaratna, M. R., Ulbrich, I. M., Ng, N. L., Worsnop, D. R., and Sun, Y. L.: Understanding atmospheric organic aerosols via factor analysis of aerosol mass spectrometry: a review, Anal. Bioanal. Chem., 401, 3045-3067, 2011.

Zhao, Y., Hallar, A. G., and Mazzoleni, L. R.: Atmospheric organic matter in clouds: exact masses and molecular formula identification using ultrahigh-resolution FT-ICR mass spectrometry, Atmos. Chem. Phys., 13, 12343-12362, https://doi.org/10.5194/acp-13-12343-2013, 2013. 